\title{
\#USGS
}

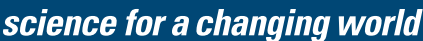

Prepared in cooperation with the Bureau of Land Management under Interagency Agreement L10PG00804 for the project: "Forecasting Insect Community Responses to Changes in Land Management and Climate in Upper Columbia Basin Sagebrush Steppe"

\section{Insect Community Responses to Climate and Weather Across Elevation Gradients in the Sagebrush Steppe, Eastern Oregon}

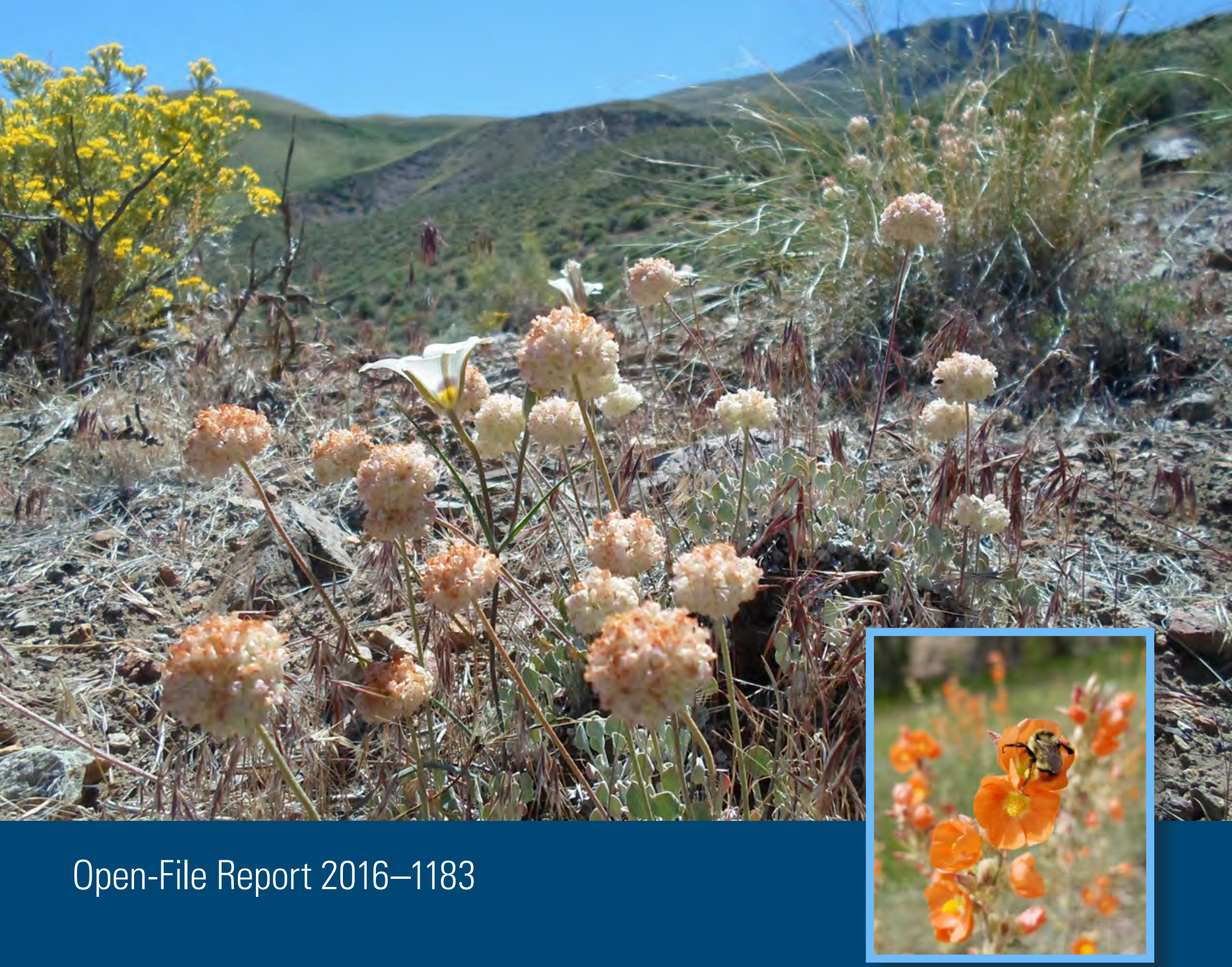

\section{U.S. Department of the Interior U.S. Geological Survey}


Cover: Photograph showing native and non-native vegetation at the Stinkingwater Mountains, Harney County, Oregon. Photograph by Ashley Rohde, 2013.

Inset: Bumble bee (Bombus sp.) on Scarlet Globemallow (Sphaeralcea coccinea). Photograph by David Pilliod, 2016. 


\section{Insect Community Responses to Climate and Weather Across Elevation Gradients in the Sagebrush Steppe, Eastern Oregon}

By David S. Pilliod and Ashley T. Rohde

Prepared in cooperation with the Bureau of Land Management under Interagency Agreement L10PG00804 for the project: "Forecasting Insect Community Responses to Changes in Land Management and Climate in Upper Columbia Basin Sagebrush Steppe"

Open-File Report 2016-1183

U.S. Department of the Interior

U.S. Geological Survey 



\title{
U.S. Department of the Interior SALLY JEWELL, Secretary
}

\section{U.S. Geological Survey Suzette M. Kimball, Director}

\author{
U.S. Geological Survey, Reston, Virginia: 2016
}

For more information on the USGS—-the Federal source for science about the Earth, its natural and living resources, natural hazards, and the environment-visit http://www.usgs.gov/ or call 1-888-ASK-USGS (1-888-275-8747).

For an overview of USGS information products, including maps, imagery, and publications, visit http://store.usgs.gov.

Any use of trade, firm, or product names is for descriptive purposes only and does not imply endorsement by the U.S. Government.

Although this information product, for the most part, is in the public domain, it also may contain copyrighted materials as noted in the text. Permission to reproduce copyrighted items must be secured from the copyright owner.

Disclaimer: This final progress report is being submitted to the Oregon State Office Bureau of Land Management to provide a summary of findings, accomplished deliverables to date, and proposed products. This information is preliminary and is subject to revision. It is being provided to meet the need for timely best science information. The assessment is provided on the condition that neither the U.S. Geological Survey nor the U.S. Government may be held liable for any damages resulting from the authorized or unauthorized use of the preliminary information. This project was supported by funding from Bureau of Land Management and the U.S. Geological Survey.

Suggested citation:

Pilliod, D.S., and Rohde, A.T., 2016, Insect community responses to climate and weather across elevation gradients in the Sagebrush Steppe, eastern Oregon: U.S. Geological Open-File Report 2016-1083, 50 p., https://doi.org/10.3133/ofr20161183. 


\section{Contents}

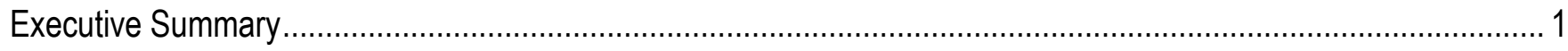

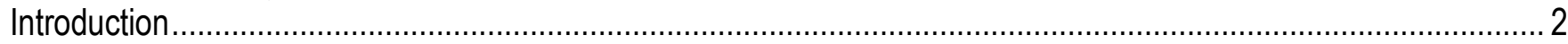

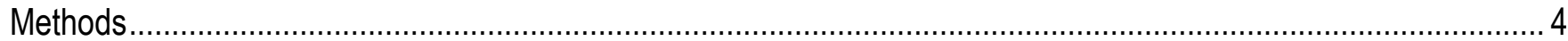

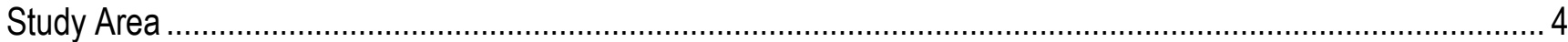

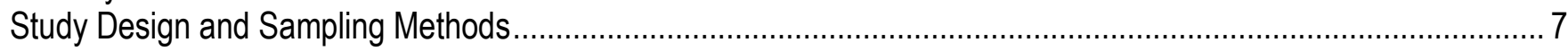

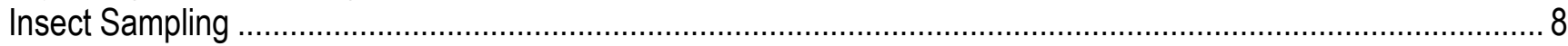

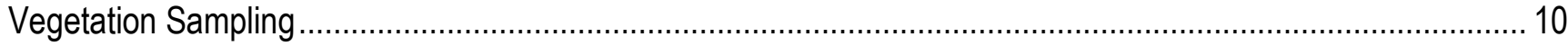

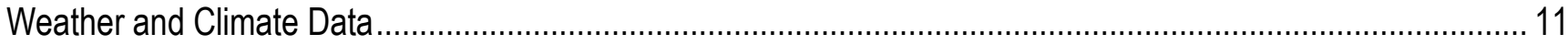

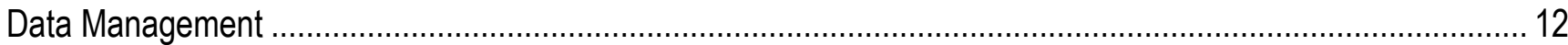

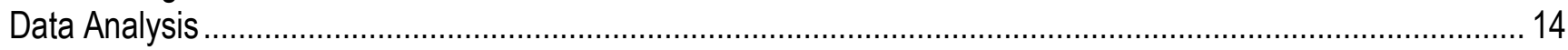

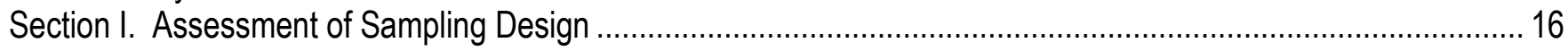

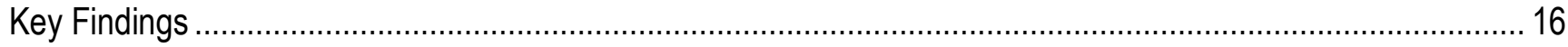

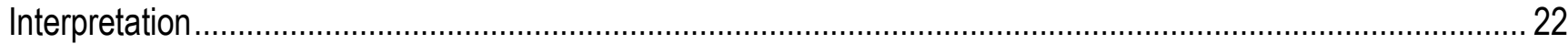

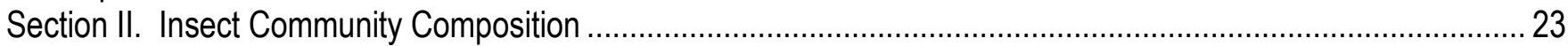

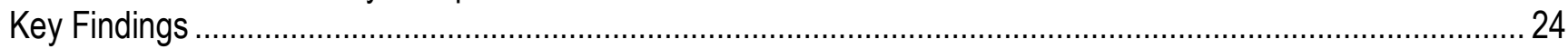

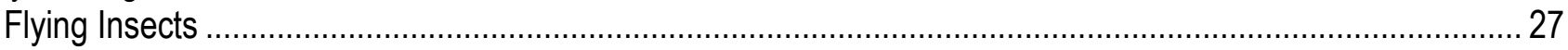

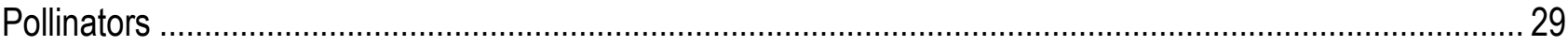

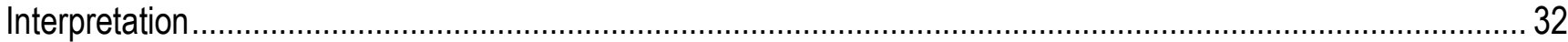

Variability in Climate, Weather, and Habitat Affected Richness, Diversity, and Evenness of Insect

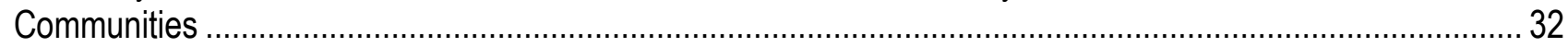

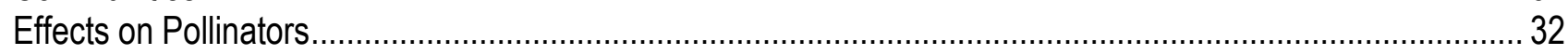

Invasive Annual Grasses Affected the Distribution of Insects Among Plots ................................................. 32

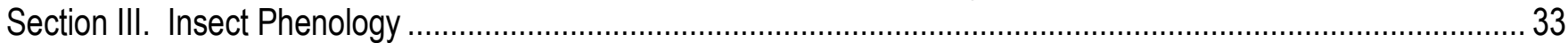

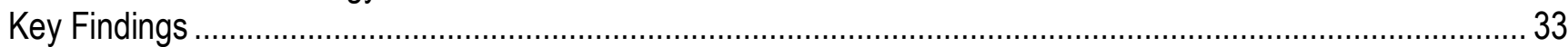

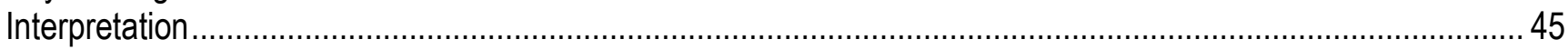

Weather, Elevation, and the Timing of Emergence and Diapause ........................................................... 45

Variability in Guild Abundance Throughout the Active Season................................................................... 46

Pollinators, Seasonality, and Climate Change .................................................................................. 46

Management Implications and Future Directions................................................................................... 46

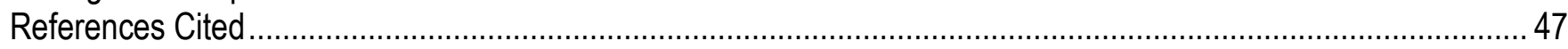




\section{Figures}

Figure 1. Map showing study areas (red stars) were located in the jurisdiction of the Burns Field Office, in Harney County, Oregon...

Figure 2. Map showing two transects (red lines) along eastern facing slopes in the Stinkingwater

Mountains (top panel) and Pueblo Mountains (bottom panel), Oregon.

Figure 3. Photographs showing vegetation at the highest and lowest sampling plots at the Stinkingwater

and Pueblo Mountains study areas..........................................................................................................

Figure 4. Diagram of pitfall and flight traps located in 1-ha plots.

Figure 5. Photographs showing pitfall traps (left) with low toxicity antifreeze and Japanese beetle flight traps (right top and bottom) with insecticide were used to capture insects at each plot, Pueblo and Stinkingwater Mountains, Oregon.

Figure 6. Photographs showing (left) one of multiple nadir photographs of vegetation sampling quadrats used with SamplePoint software (Booth and others, 2006) to quantify the percent cover of vegetation and abiotic habitat characteristics at each plot; and (right) point-centered quarter method used to sample and quantify the percent cover of native bunchgrasses and forbs at each plot.

Figure 7. Photographs showing examples of how weather stations were placed at the mid-elevation plots at each transect in 2012 and at every elevation along each transect in 2013, Stinkingwater and Pueblo Mountains, Oregon.....

Figure 8. Graph showing sampling plots from Stinkingwater and Pueblo Mountains study areas grouped into four elevation classes

Figure 9. Non-metric multidimensional scaling analysis shows that, regardless of elevation, insect community composition at plots from the Pueblo Mountains study area were more similar to each other than to that at the plots from the Stinkingwater Mountains (Stink) study area ...

Figure 10. A depiction of the predicted relationships among elevation, climate, weather, vegetation, and insects. We predicted that elevation would affect both climate and weather ....

Figure 11. Linear regression analysis showing that plots at high elevations had low 30-year average air temperatures and high 30-year average precipitation, Stinkingwater and Pueblo Mountain study areas,

Oregon.

Figure 12. Bubble graph showing the number of insect families captured for the first time or the last time at each sampling elevation and at what time during the season they were captured, Stinkingwater and Pueblo Mountains, Oregon

Figure 13. Average timing of first capture for all families grouped by feeding guilds was significantly different among elevations in 2012 (large windows, table 11), Stinkingwater and Pueblo Mountains, Oregon.

Figure 14. Non-metric multidimensional scaling showing that insect samples from different events during the sampling season changed somewhat systematically, with the mean value for each month shifting through ordination space.

Figure 15. Peak abundance of families captured during every sampling event, Stinkingwater and Pueblo Mountains, Oregon

Figure 16. Abundances of insects by feeding guilds throughout the sampling season in 2012

Figure 17. Abundance of herbivores and predators varied among elevations within sampling events, Stinkingwater and Pueblo Mountains, Oregon.

Figure 18. Abundance of pollinators from early June to October 2012 at the Stinkingwater and Pueblo Mountain study areas, Oregon 


\section{Tables}

Table 1. Sampling design for 2012 and 2013, Pueblo and Stinkingwater Mountains, Oregon...............................8

Table 2. All pairwise comparisons of weather between study areas at different sampling events were significant at $p<0.001$, Stinkingwater and Pueblo Mountain study areas.

Table 3. Pairwise comparisons of least squares means at all sampling events, Stinkingwater and Pueblo Mountain study areas, Oregon, 2012 and 2013...

Table 4. Multi-response permutation procedure comparisons of weather between transects at every sampling event at the Pueblo and Stinkingwater Mountain study areas, Oregon, 2012

Table 5. Solar radiation was significantly different between transects within Stinkingwater and Pueblo Mountain study areas, Oregon, 2012

Table 6. Associations between climate and elevation indicate that the variability of air temperature among years, rather than maximum, median, or minimum air temperatures, has the strongest association with elevation at the Stinkingwater and Pueblo Mountain study areas, Oregon...

Table 7. Guild-level associations between richness of insect families and environmental variables indicate that insects are associated with climate and vegetation at the Stinkingwater and Pueblo Mountain study areas, Oregon.

Table 8. Community-level analyses of changes in insect richness, diversity, and evenness with changes in environmental variables between 2012 and 2013 indicate that the community is affected by interannual variability in weather and vegetation at Stinkingwater and Pueblo Mountain study areas, Oregon.

Table 9. Guild-level analyses of the relationship between interannual changes in insect richness, diversity, and evenness and interannual changes in environmental variables at the Stinkingwater and Pueblo Mountain study areas, Oregon.

Table 10. Analyses of orders within the nectarivore guild indicate that pollinators from different orders are sensitive to changes in different weather and vegetation variables Stinkingwater and Pueblo Mountain study areas, Oregon.

Table 11. Multi-response permutation procedure analysis indicates differences in timing of first and last captures of families within feeding guilds among elevations in 2012.

Table 12. Timing of first and last capture of insect families within guilds was strongly associated with measured weather variables at the Stinkingwater and Pueblo Mountain study areas, Oregon.

Table 13. Multi-response permutation procedure analysis was used to compare weather among sampling events and among elevations nested within sampling events at our plots located at the Stinkingwater and Pueblo Mountains, Oregon.

Table 14. Composition of insect guilds was significantly different among sampling events and elevations within events.

Table 15. Guilds were associated with weather variables to varying degrees at the Stinkingwater and Pueblo Mountain study areas, Oregon

Table 16. Differences in composition and abundances in nectarivorous orders of insects among events and elevations within events.

Table 17. Associations between nectarivorous insect orders and weather variables 


\section{Conversion Factors}

International System of Units to U.S. Customary Units

\begin{tabular}{|c|c|c|}
\hline Multiply & By & To obtain \\
\hline \multicolumn{3}{|c|}{ Length } \\
\hline centimeter (cm) & 0.3937 & inch (in.) \\
\hline meter (m) & 3.281 & foot (ft) \\
\hline meter (m) & 1.094 & yard (yd) \\
\hline kilometer (km) & 0.6214 & mile (mi) \\
\hline kilometer (km) & 0.5400 & mile, nautical (nmi) \\
\hline \multicolumn{3}{|c|}{ Area } \\
\hline square meter $\left(\mathrm{m}^{2}\right)$ & 0.0002471 & acre \\
\hline square meter (m2) & 10.76 & square foot (ft2) \\
\hline hectare (ha) & 2.471 & acre \\
\hline hectare (ha) & 0.003861 & square mile $\left(\mathrm{mi}^{2}\right)$ \\
\hline
\end{tabular}

Temperature in degrees Celsius $\left({ }^{\circ} \mathrm{C}\right)$ may be converted to degrees Fahrenheit $\left({ }^{\circ} \mathrm{F}\right)$ as ${ }^{\circ} \mathrm{F}=\left(1.8 \times{ }^{\circ} \mathrm{C}\right)+32$.

\section{Datums}

Horizontal coordinate information is referenced to the North American Datum of 1983 (NAD 83).

Vertical coordinate information is referenced to the North American Vertical Datum of 1988 (NAVD 88). Elevation, as used in this report, refers to distance $(\mathrm{m})$ above sea level. 


\title{
Insect Community Responses to Climate and Weather Across Elevation Gradients in the Sagebrush Steppe, Eastern Oregon
}

\author{
David S. Pilliod and Ashley T. Rohde
}

\section{Executive Summary}

In this study, the U.S. Geological Survey investigated the use of insects as bioindicators of climate change in sagebrush steppe shrublands and grasslands in the Upper Columbia Basin. The research was conducted in the Stinkingwater and Pueblo mountain ranges in eastern Oregon on lands administered by the Bureau of Land Management.

We used a "space-for-time" sampling design that related insect communities to climate and weather along elevation gradients. We analyzed our insect dataset at three levels of organization: (1) whole-community, (2) feeding guilds (detritivores, herbivores, nectarivores, parasites, and predators), and (3) orders within nectarivores (i.e., pollinators). We captured 59,517 insects from 176 families and 10 orders at the Pueblo Mountains study area and 112,305 insects from 185 families and 11 orders at the Stinkingwater Mountains study area in 2012 and 2013. Of all the individuals captured at the Stinkingwater Mountains study area, 77,688 were from the family Cecidomyiidae (Diptera, gall gnats).

We found that the composition of insect communities was associated with variability in longterm (30-yr) temperature and interannual fluctuations in temperature. We found that captures of certain fly, bee, moth, and butterfly pollinators were more strongly associated with some climate and vegetation variables than others. We found that timing of emergence, as measured by first detection of families, was associated with elevation. When analyzed by feeding guilds, we found that all guilds emerged later at high elevations except for detritivores, which emerged earlier at high elevations. The abundance of most taxa varied through time, mostly in response to temperature and precipitation. Of the pollinators, bees (particularly, Halictidae and Megachilidae) peaked in abundance in late June and early July, whereas butterflies and moths peaked in August. Flies peaked in abundance in July.

Overall, our interpretation of these patterns is that insect communities respond positively and negatively to weather and local vegetation more than to long-term climate. Given increasing variability in weather and high probability of extreme weather events, insect communities in sagebrush steppe also may experience considerable fluctuations in composition and abundance, as well as phenology. These findings have implications for many ecosystem services, including pollination, decomposition, and food resources for predatory birds and other vertebrates. 


\section{Introduction}

Climate, in large part, determines the distribution of plants and animals. Recent accelerated climate change caused by human activities appears to be no exception. Globally, lower snowpacks, earlier springs, new rainfall patterns, and warmer temperatures have been measured over the last $50-60$ years (Karl and others, 2009). Since the late 1800s, the planet has warmed approximately $0.85^{\circ} \mathrm{C}$, mostly because of an increase in minimum annual temperatures (Pachauri and Meyer, 2014). Populations of plants and animals may respond to changing climate by dispersing to new sites with more suitable conditions (climate tracking) or adapting genetically or phenotypically to the new environmental conditions. However, the natural expansion and contraction of species ranges associated with climate deviations may be influenced by human-associated barriers or stressors, such as land use, natural disturbances (like fire), or invasive species (Vitousek, 1994; Vitousek and others, 1996; Sala and others, 2000). If species are unable to move or adapt, then they are more likely to go locally or even regionally extinct (Hill and others, 2011).

Investigations of range shifts associated with recent climate change often are focused on the leading edge of distributions with colonization occurring along high latitudes and elevations, where environmental variables are more favorable under changing conditions. A study that measured the distribution of 37 species of dragonflies in Britain concluded that the ranges of southern species are shifting northward (Hickling and others, 2005). Two species whose ranges already extended to the northernmost limits of Britain were found to be retracting in distribution from their southern boundary (Hickling and others, 2005). Within the plant communities of southern California's Santa Rosa Mountains, species were reported to shift an average of almost $65 \mathrm{~m}$ higher in elevation from 1977 to 2006 (Kelly and Goulden, 2008).

Phenological responses to climate change also have been documented. In a meta-analysis of 61 studies considering 694 species or groups of species, Root and others (2003) found that springtime events of some populations are as many as 24 days earlier than they were $50-100$ years ago. When several groups of organisms were considered separately, invertebrates, amphibians, non-tree plants, and birds had springtime phenologies that were five days earlier currently than historically. Trees had altered their phenologies by three days (Root and others, 2003). It is unclear whether these changes are due to genetic adaptation or genetic plasticity, but changes in genotype frequencies have been linked with climate change (Gienapp and others, 2007).

Insects are good model organisms for measuring the effects of climate change because of their short generation times, relatively rapid responses to disturbance, and large population sizes. They are among the easiest and least expensive animal taxa to collect, allowing robust sample sizes for statistical analysis using relatively high-level taxonomic identification for economical and swift results (Williams and Gaston, 1994; Cagnolo and others, 2002; Riggins and others, 2009). Moreover, arthropods are critically important members of their communities because they occupy the widest variety of niches and play more ecological roles than any other group of animals (Longcore, 2003). Insects are among the most important pollinators on the planet and are a major food source for many vertebrates (McGee, 1982; Williams, 1984; Johnson and Boyce, 1990; Crawford and others, 2004). 
The topic of this report is especially timely because of a recent Presidential Memorandum, the Pollinator Research Action Plan (The White House, 2015), that draws national attention to restoration and preservation of habitat for pollinators across the country. This plan identifies key priority research themes including: (1) Understanding pollinator habitat requirements and (2) Understanding habitat loss, degradation, and fragmentation effects on pollinators, as well as stressors that interact with and exacerbate these effects. Additionally, the Greater Sage-Grouse Approved Resource Management Plan Amendment (BLM/OR/A/PL-15/051+1792) released by the Bureau of Land Management (2015) identifies priority sage-grouse habitat management areas in multiple states including over 9.7 million acres (3.9 million hectares [ha]) in Oregon and over 2.8 million acres (1.1 million ha) in Harney County, Oregon, where the research study areas for this study were located. Insects are a critical food source for juvenile sage-grouse (Johnson and Boyce, 1990; Drut and others, 1994).

In this study, we quantified insect community composition along an elevation gradient to make predictions about relationships between insects and climate in a semi-arid shrubland. Insects have been shown to experience and respond to changes in climate along elevation gradients, particularly differences in temperature and precipitation (Warren and others, 1988; Hodkinson, 2005).

The original proposal addressed the following research questions:

- What is the current composition and abundance of families in the insect community across elevation gradients in sagebrush steppe?

- Does composition of insect communities vary between study areas or between transects within study areas?

- How does interannual variation in weather and habitat affect composition and abundance in the insect community?

- How do changes in elevation and associated habitat factors affect the phenology (for example emergence and diapause [a period of suspended development, often during the winter for temperate species]) of different taxa?

This study was designed in two phases: a short-term study of the differences in composition and phenology of insects along elevation gradients, and a long-term study measuring the changes in species ranges and phenology over 10 years or more at the same established sampling plots. The first phase of this study has been completed and the results are reported here. We organized the major findings into three sections: an assessment of sampling design with considerations of the differences in measured variables between study areas and between transects within study areas (Section I. Assessment of Sampling Design), an assessment of the insect community composition and associations with climate, weather, and habitat (Section II. Insect Community Composition), and an assessment of insect phenology (emergence, diapause, and seasonal abundance) in relation to elevation, weather, and habitat (Section III. Insect Phenology). The detailed questions addressed in each section were derived from the research questions in the original proposal and are listed at the beginning of each section. 


\section{Methods}

\section{Study Area}

We established four transects along an elevation gradient within the Stinkingwater (elevation 1,150 to 1,600 m) and Pueblo (elevation 1,300 to 1,850 m) mountain ranges in southeastern Oregon (figs. 1 and 2). Study areas were located $168 \mathrm{~km}$ apart. Transects at the Stinkingwater Mountains study area were $19 \mathrm{~km}$ apart and transects at the Pueblo Mountains study area were $9 \mathrm{~km}$ apart. These four transects serve as replicates. Study areas were within the jurisdiction of the Burns Field Office, Harney County, Oregon, managed by the Bureau of Land Management.

Sagebrush steppe vegetation spans over 44.4 million ha of land in the western United States (Miller and Edelman, 2000), and more than 80 percent of this land is affected by anthropogenic activities (West, 1999). Reductions in biodiversity due to climate change are predicted to be most severe in Mediterranean climate and grassland ecosystems (Sala and others, 2000), such as sagebrush steppe. These systems may be particularly susceptible to climate change because of their aridity, and high amount of habitat conversion and low amount of protected land relative to other major habitat types (Hoekstra and others, 2005).

In addition to climate change, land use and non-native species are predicted to effect semi-arid grasslands and sagebrush steppe (Sala and others, 2000). Historical mismanagement of cattle grazing, invasive annual grasses, and fire regime changes cause fragmentation and reduction of habitat that complicate organisms’ responses to climate stressors (Knick, 1999; fig. 3). Restoration and rehabilitation efforts, mostly implemented by federal and state agencies, attempt to mitigate these effects, but often with mixed results (West, 1999; Arkle and others, 2014). 


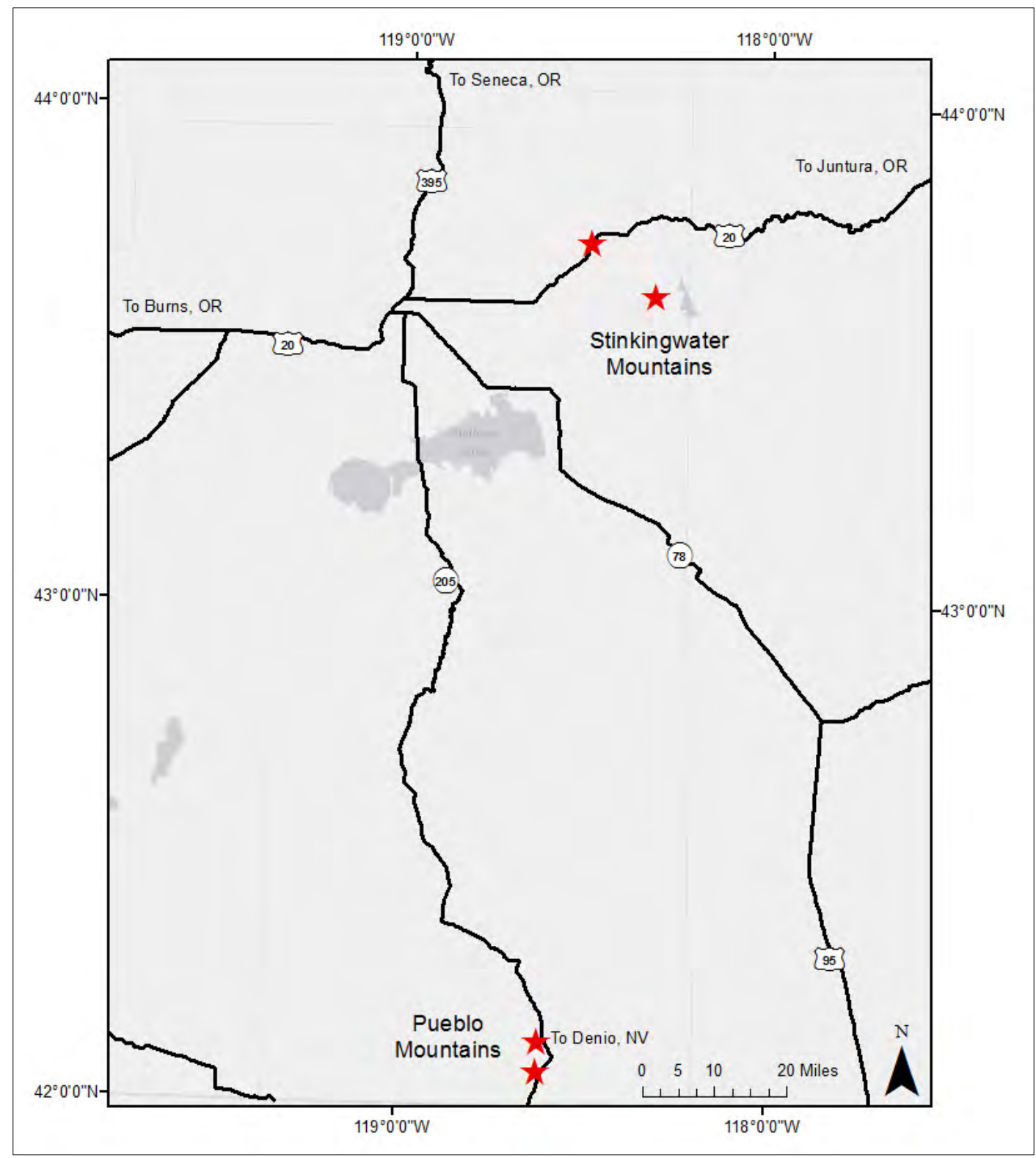

Figure 1. Map showing study areas (red stars), which were located in the jurisdiction of the Burns Field Office, in Harney County, Oregon. Base map sources: Esri, HERE, DeLorme, Mapmylndia, @ OpenStreetMap contributors, and the GIS user community. 


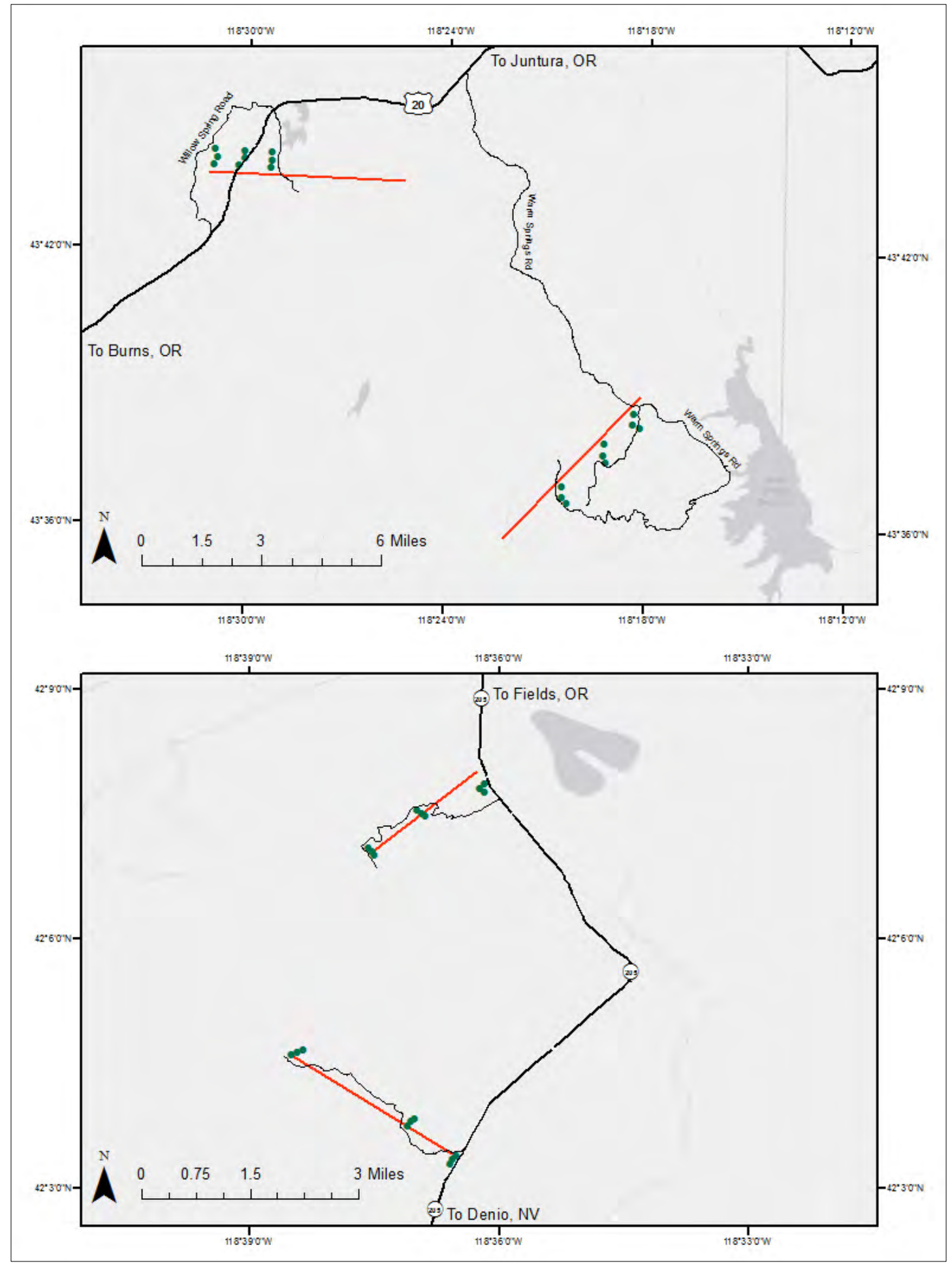

Figure 2. Map showing two transects (red lines) along eastern facing slopes in the Stinkingwater Mountains (top panel) and Pueblo Mountains (bottom panel), Oregon. We sampled at three 1-hectare plots (green dots) at three elevations along each transect, for a total of 18 plots at each study area. Base map sources: Esri, HERE, DeLorme, MapmyIndia, () OpenStreetMap contributors, and the GIS user community. 

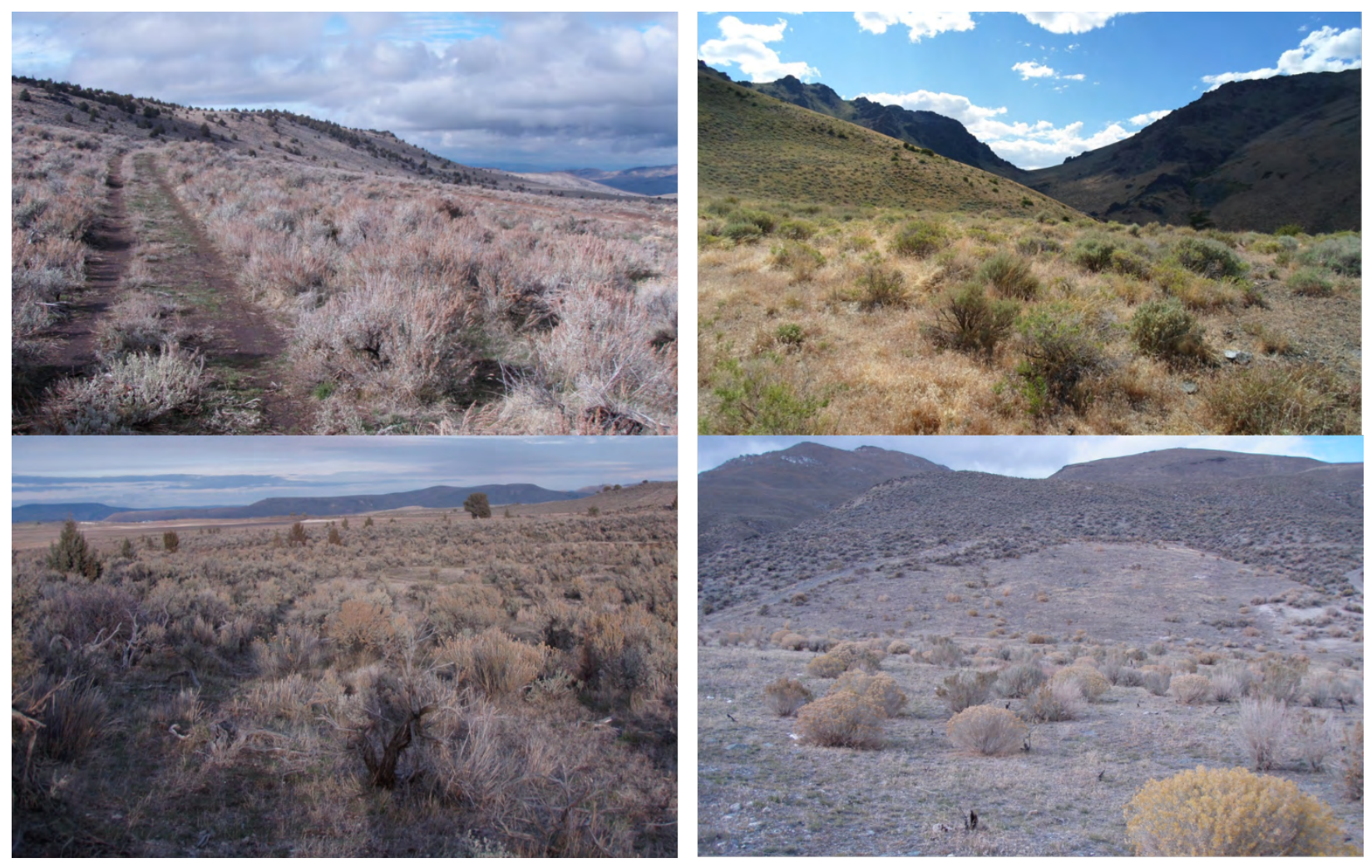

Figure 3. Photographs showing vegetation at the highest and lowest sampling plots at the Stinkingwater and Pueblo Mountains study areas. Top left: Stinkingwater high, bottom left: Stinkingwater low, top right: Pueblo high, and bottom right: Pueblo low.

\section{Study Design and Sampling Methods}

We sampled insects along an elevation gradient to quantify associations between insect community structure and climate. The elevation gradient was established as uphill transects that extended from valley bottom to ridge tops. Vegetation varies across elevation in response to climate (Whittaker and Niering, 1975). Thus, vegetation and climate were confounded in our design. We attempted to account (or control) for the relative influence of vegetation on insects by including vegetation measurements in statistical models.

We used several criteria to locate and determine the suitability of transects for sampling. All transects were chosen from slopes in eastern Oregon where vegetation was characterized by sagebrush steppe. We restricted transects to within $1 \mathrm{~km}$ of a road to provide access. We intentionally avoided areas that had been burned in the last 25 years or where vegetation had been treated (for example, seeding or herbicide treatments). We did not control for livestock grazing and all areas occurred within BLM grazing allotments. These restrictive criteria limited our ability to place transects randomly, but we attempted to maintain as much randomization as possible in transect and sample location decisions. However, given that we studied four replicate transects across two mountain ranges, we consider the inference of this study to be approximately sagebrush steppe habitats of eastern Oregon. 
Along each of the four transects, we placed nine plots clustered in groups of three. A plot was delineated as a 1-ha area and placed within $500 \mathrm{~m}$ of the transect line. The clustering was a necessity for sampling efficiency and allowed for greater sampling effort at each elevation along each transect. Groups of plots were placed so there was a minimum of $100 \mathrm{~m}$ difference in elevation between them, which resulted in variable Euclidean distances between groups of plots along transects. Plots within groups were placed so their elevations would be as similar as possible, but the centroids (where insect samples were placed) were always a minimum of $100 \mathrm{~m}$ apart.

\section{Insect Sampling}

Insect sampling was designed to quantify the insect community. We sampled biweekly from mid-May through August at all four transects in 2012 and from June through August at the northern transect at the Pueblo Mountains study area and the southern transect at the Stinkingwater Mountains study area in 2013 (table 1). We sampled monthly in September and October in 2012 only.

We sampled insects using a protocol described by Lowe and others (2010). Five pitfall traps were placed five meters from the center of each plot at compass bearings of $36^{\circ}, 108^{\circ}, 180^{\circ}, 252^{\circ}$, and $324^{\circ}$. Pitfall traps were filled approximately 25 percent with low toxicity antifreeze. Pitfall traps contained no olfactory or visual baits and therefore were considered passive traps. Insects were expected to fall into these traps while walking on the ground. We placed one yellow- and one blue-colored Japanese beetle flight trap (Great Lakes IPM, Inc., http://www.greatlakesipm.com/) at each plot, 10 meters from the center. The placement of the first trap was randomly chosen and the second was placed $180^{\circ}$ from the first (figs. 4 and 5). The traps contained no olfactory baits. The colors of these traps were intended to mimic flowers and attract flying insects. Blue and yellow traps are often used to mimic the color of flowers within a sampling area, though there is evidence that color of an insect's primary host flower does not affect color preference for traps (Roulston and others, 2007; Wilson and others, 2008). Additionally, there is evidence that capture rates are similar between colors in the Great Basin Desert, but that composition of insect samples from the different colors are different (Wilson and others, 2008). Traps were left open for five consecutive days and nights.

Table 1. Sampling design for 2012 and 2013, Pueblo and Stinkingwater Mountains, Oregon.

[Two of four transects from 2012 were resampled in 2013]

\begin{tabular}{|c|c|c|c|c|c|c|}
\hline Year & Transects & $\begin{array}{c}\text { Number } \\
\text { of 1-ha } \\
\text { plots }\end{array}$ & $\begin{array}{c}\text { Number } \\
\text { of pitfall } \\
\text { traps }\end{array}$ & $\begin{array}{c}\text { Number } \\
\text { of flight } \\
\text { traps }\end{array}$ & $\begin{array}{c}\text { Number of } \\
\text { sampling } \\
\text { events }\end{array}$ & $\begin{array}{c}\text { Total } \\
\text { traps }\end{array}$ \\
\hline 2012 & 4 & 36 & 180 & 72 & 8 & 2,016 \\
\hline 2013 & 2 & 18 & 90 & 36 & 5 & 630 \\
\hline
\end{tabular}




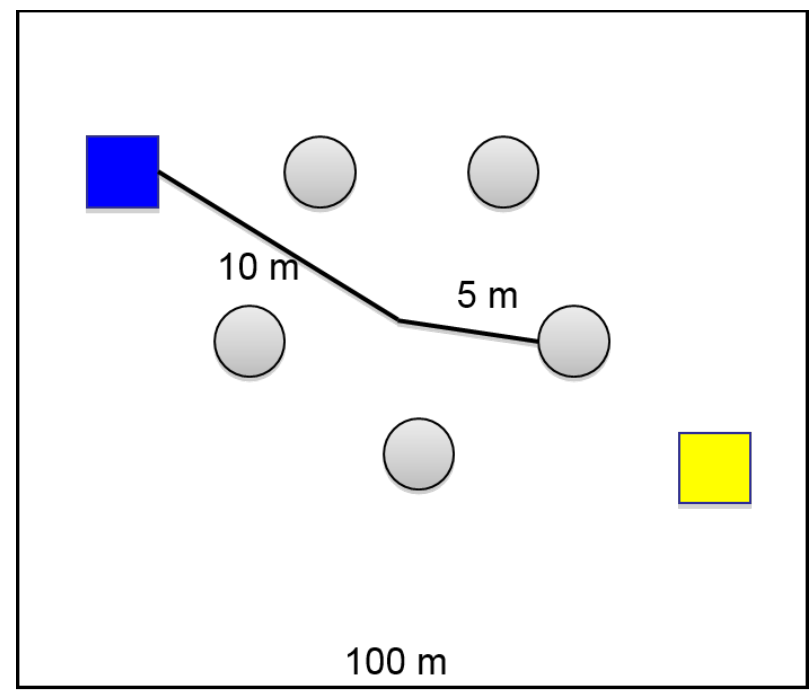

Figure 4. Diagram of pitfall and flight traps located in 1-ha plots. Two flight traps, one yellow and one blue, were placed 10 meters from the center of each plot and oriented $180^{\circ}$ from each other. The outer square represents the boundary of a 1-ha sample plot with $100 \mathrm{~m}$ per side.
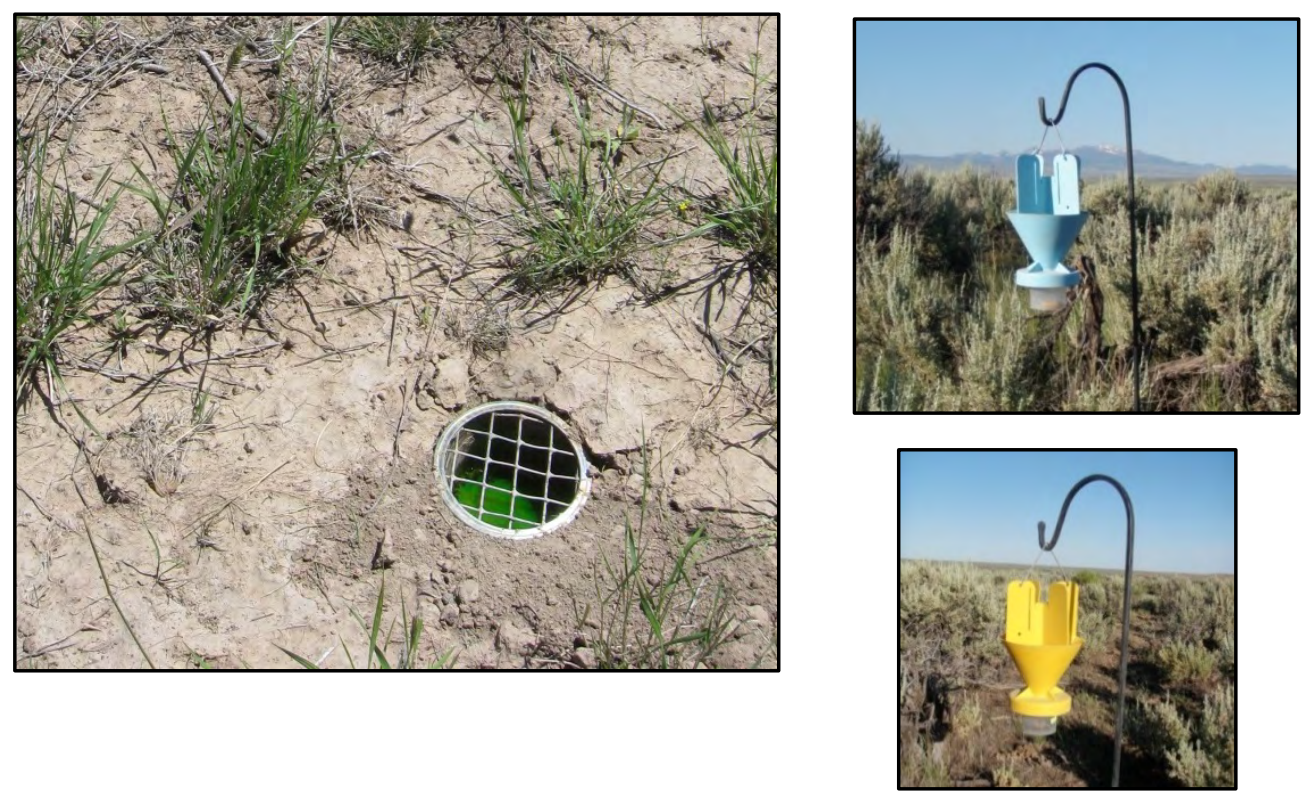

Figure 5. Photographs showing pitfall traps (left) with low toxicity antifreeze and Japanese beetle flight traps (right top and bottom) with insecticide. These traps were used to capture insects at each plot, Pueblo and Stinkingwater Mountains, Oregon. 


\section{Vegetation Sampling}

Within each 1-ha plot, we randomly placed six vegetation sampling quadrats with the constraint that each quadrat had to be at least $20 \mathrm{~m}$ from any other. Each quadrat measured approximately $1.5 \times$ $1.5 \mathrm{~m}$ of ground area. We first created a list of all species present in the quadrat and then photographed the quadrat using a Canon Powershot A590 IS digital camera fixed to a 2 meter monopod (fig. 6). This is the height recommended by Booth and others (2006) for use of this technique in sagebrush habitats. In the field, we also recorded the height of several functional groups of vegetation: shrubs, native forbs, native bunch grasses, and non-native annual grasses that occurred within each quadrat.

In the laboratory, we measured percent cover by species in each photo-quadrat using SamplePoint software (Booth and others, 2006), which is a grid-point-intercept method (Pilliod and Arkle, 2013). We used the species list for each quadrat that had been created in the field for reference. An oversampling effort conducted by Pilliod and Arkle (2013) determined that six photo-quadrats were needed to accurately represent the spatial heterogeneity of vegetative ground cover in a 1-ha sagebrush or grassland plot. However, earlier work also had shown that bunch grasses and shrubs tend to be underrepresented in quadrats.

Therefore, we measured the density and cover of native bunch grasses and shrubs using pointcentered quarter method (hereafter point-quarter, fig. 6). We sampled using point-quarter from the center of each of the six photo-quadrats within each 1-ha plot. Within each of the four quadrants around each sampling point, we measured the distance from the sampling point to the canopy center of the nearest: (1) mature native bunchgrass (canopy-line intercept $>15 \mathrm{~cm}$ ), and (2) shrub (canopy-line intercept $>10 \mathrm{~cm}$ ), for a maximum of 4 bunchgrasses and 4 shrubs per sample point (maximum of 36 bunch grasses and 36 shrubs per 1-ha plot). Search distances from sampling points to the nearest bunchgrass, shrub, or juniper were limited to $20 \mathrm{~m}$ to avoid measuring an individual plant from multiple sample points. We also recorded the species and canopy-line intercept of each plant. Canopy-line intercept was measured through the same portion of the plant used to measure the distance from the sample point to the plant (on the axis from the sample point to the canopy center). The intercept value was recorded as the number of centimeters between the point on the meter tape first intersected by any part of the plant and the last point on the meter tape intersected by any part of the plant after turning the meter tape such that its width was perpendicular to the ground.
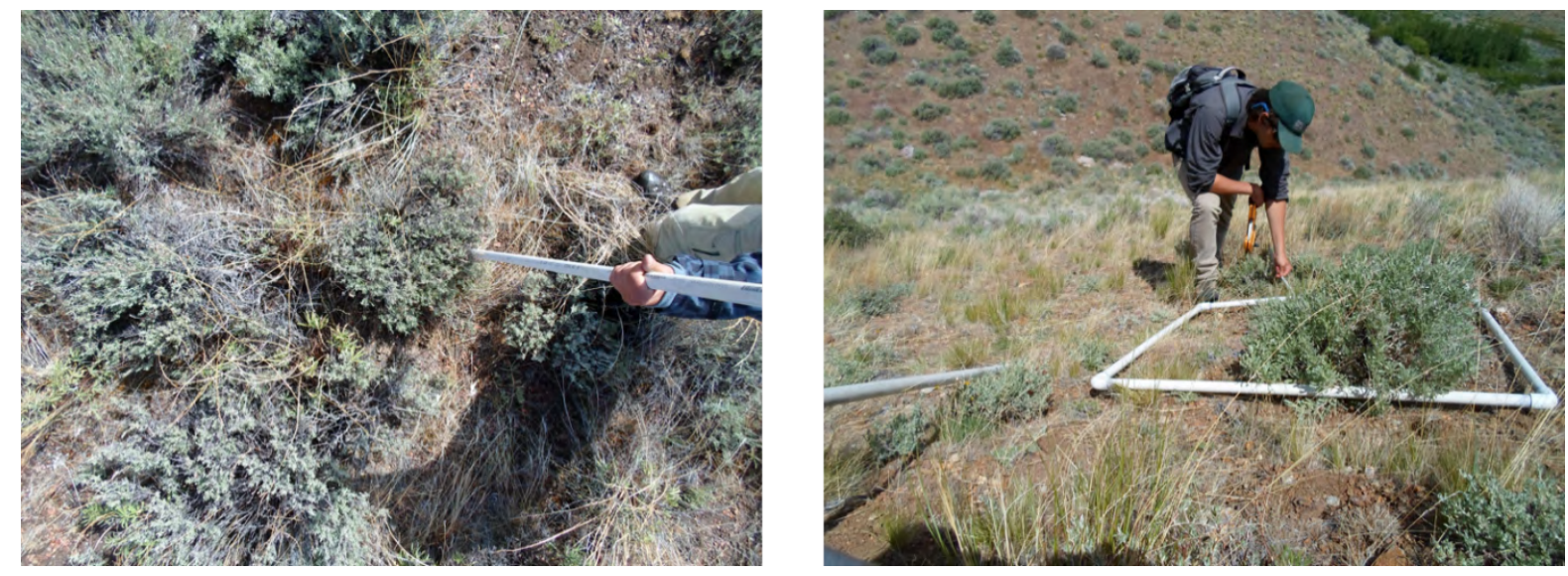

Figure 6. Photographs showing (left) one of multiple nadir photographs of vegetation sampling quadrats used with SamplePoint software (Booth and others, 2006) to quantify the percent cover of vegetation and abiotic habitat characteristics at each plot; and (right) point-centered quarter method used to sample and quantify the percent cover of native bunchgrasses and forbs at each plot. 


\section{Weather and Climate Data}

We measured local ground temperature by placing iButton ${ }^{\circledR}$ data loggers (Maxim Integrated Products, Sunnyvale, CA, USA) at each elevation along each transect (fig. 7). We installed weather stations at the mid elevation plots of each transect during the sampling season of 2012 and at high, mid and low elevation plots during the 2013 sampling season (fig. 7). Weather stations were installed approximately one meter above the ground and measured air temperature, solar radiation, and soil moisture. Weather variables for plots without weather stations in 2012 were estimated using iButton data and data from weather stations used in 2013. We calculated growing degree days from measured air temperature data using equation 1.

$$
\mathrm{GDD}=\frac{\operatorname{Tmax}+\mathrm{Tmin}}{2}-10^{\circ} \mathrm{C}
$$

where

$$
\begin{aligned}
\text { GDD } & =\text { Growing Degree Days, } \\
\text { Tmax } & =\text { maximum temperature, and } \\
\text { Tmin } & =\text { minimum temperature. }
\end{aligned}
$$

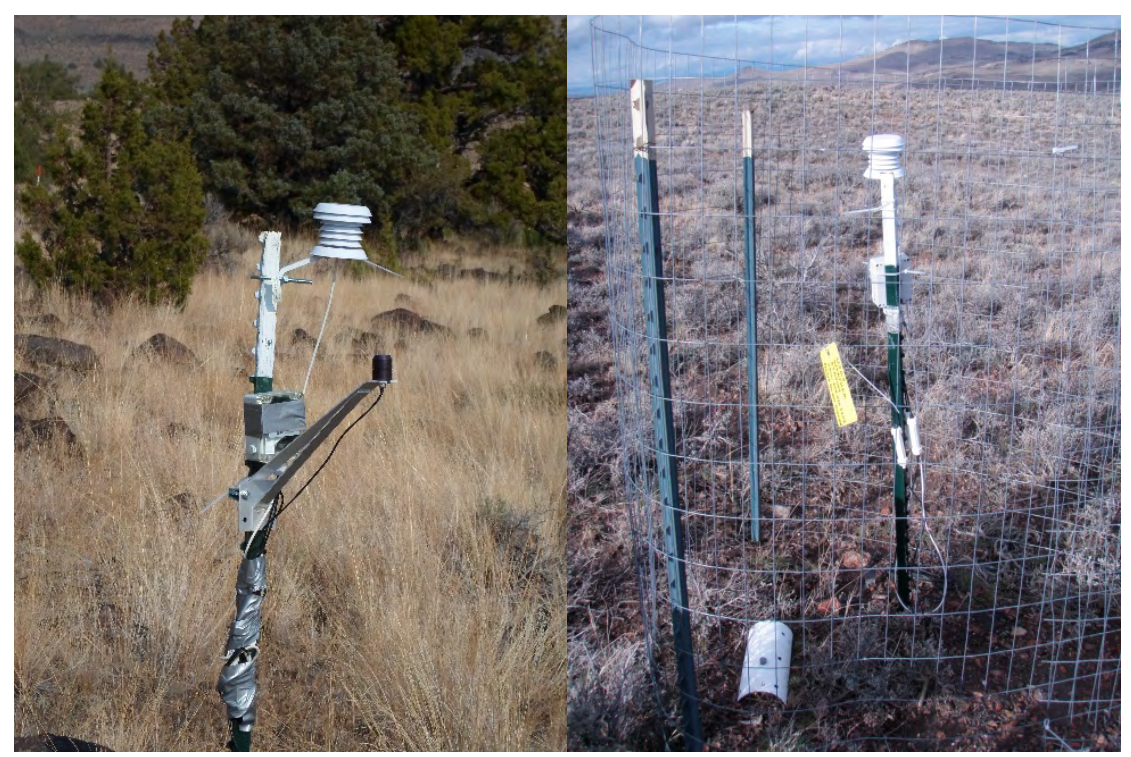

Figure 7. Photographs showing examples of how weather stations were placed at the mid-elevation plots at each transect in 2012 and at every elevation along each transect in 2013, Stinkingwater and Pueblo Mountains, Oregon. Cords and seals were covered with duct tape to provide extra protection from weather and wildlife. Right photograph also shows the iButton ${ }^{\circledR}$ ground temperature recorder covered by a solar shield (white half-round PVC). 
Thirty-year averages of climate variables were collected from daily DayMet data (Thornton and others, 2014) and a nearby National Oceanic and Atmospheric Administration weather station (Bald Mountain, Oregon; Latitude: 43 33' 20" Longitude: 118²4' 15", https://www.ncdc.noaa.gov/dataaccess/land-based-station-data https://www.ncdc.noaa.gov/data-access/land-based-station-data) and adjusted to estimate local climate using the 2013 iButton ${ }^{\circledR}$ and weather station data. This provided estimates of 30-year climate variables for each elevation group (three plots) along each transect. These data were used to derive biologically meaningful climate variables using the Bioclim model (www.worldclim.org/bioclim). For example, we measured the 30-year average of the daily maximum temperature in the warmest annual quarter (that is, summer) and the minimum daily temperature in the coldest annual quarter (that is, winter). The months included in these quarters were variable among plots, depending on temperature patterns at those plots. These variables provide good estimates of the temperature stressors that insects have to tolerate within the sampling plots over a period of thirty years. We also measured the 30-year average of cumulative precipitation during the wettest and driest quarters at each plot. These variables provide good estimates of long-term seasonal water availability at the sampling plots. Future sections of this report refer to weather and climate. In this study, we use the word "weather" in reference to measured (ground and air) temperature and precipitation variables during the sampling period. We use the word "climate" in reference to the long-term (in this case 30 years; 19822012) pattern of air temperature and precipitation at the study areas.

\section{Data Management}

Percent cover of vegetation and abiotic environmental characteristics were summarized to the plot level and then averaged for each elevation. Species and abiotic characteristics were grouped into seven functional groups: soil, rock, bunchgrasses, biological crust and moss, forbs (including nonnative), invasive grasses, and shrubs. These data were derived from the grid-point intercept, except for percent cover of bunchgrasses and shrubs, which were calculated from point-quarter sampling.

Insects were sorted and identified to the level of family. Family-level diversity has been shown to closely parallel species-level diversity in many taxa including woody plants (Balmford and others, 1996), ferns, bats, passerine birds (Williams and Gaston, 1994), aquatic macroinvertebrates (Heino and Soininen, 2007), and terrestrial invertebrates (Williams and Gaston, 1994; Cagnolo and others, 2002;

Riggins and others, 2009). Restricting identification to this relatively high taxonomic level allowed us to sample and identify many more organisms than if they had been identified to species or genus, consequently allowing us to broaden our temporal sampling and our area of inference. 
Insects were analyzed at three levels of organization: community, feeding guild, and order within feeding guild. At the finest level of organization, orders within feeding guild, we analyzed only orders within the nectarivore guild because nectarivorous insects are important pollinators in this system and, therefore, we had an interest in their specific climate associations. We calculated the detected insect family richness (number of families captured) and insect abundance at each level of organization at each study area in 2012 and 2013. We estimated insect family richness using the Chao 1 richness estimator (Chao and Jost, 2012) using EstimateS software (Colwell, 2013) and estimated diversity and evenness using Shannon's diversity (eq. 2) and evenness (eq. 3). We expected that insect abundance would be most strongly influenced by interannual changes in weather, which would in turn affect detectability of rare families and skew richness. To accommodate this possible sampling bias, we included Shannon's diversity and evenness, as well as richness, in our insect-weather dataset. Indices of diversity and evenness account for both richness and abundance of families within the community. We used the Chao 1 richness estimator to estimate true richness based on detected richness and detection probability (Chao and Jost, 2012) to account for detection bias associated with interannual changes in abundance (detectability) in our insect-climate dataset.

$$
\begin{gathered}
\mathrm{H}^{\prime}=\sum_{i=1}^{\mathrm{s}} p_{i} \ln p_{i} \\
\mathrm{E}_{\mathrm{H}}=\mathrm{H} / \ln \mathrm{S}
\end{gathered}
$$

where

$\begin{aligned} \mathrm{H}^{\prime} & =\text { Shannon's diversity index, } \\ \mathrm{S} & =\text { total number of families in the community, } \\ p_{i} & =\text { proportion of } \mathrm{S} \text { made up of the ith species, and } \\ \mathrm{E}_{\mathrm{H}} & =\text { evenness. }\end{aligned}$




\section{Data Analysis}

In Section I, Assessment of Sampling Design, we compared climate, weather, vegetation, and insect community composition among study areas and transects within study areas. To make these comparisons, we used data that were collected at plots from each study area that overlapped in elevation. We grouped plots from Stinkingwater and Pueblo Mountains study areas into elevation classes and compared plots from study areas within elevation classes (fig. 8). We included plots from classes 2 (elevation 1,200 to1,399 m) and 3 (elevation 1,400 to1,599 m), because these classes occurred at both study areas. We included vegetation measurements from 2012 and 2013 in this analysis, to include possible interannual variability in vegetation composition. We used a general relativization to scale variables with different units of measurement to comparable unitless values for multi-response permutation procedure (MRPP). We used MRPP to compare samples collected at different study areas, transects, and sampling events. We used nested ANOVA's to compare each weather variable between study areas and among transects separately.

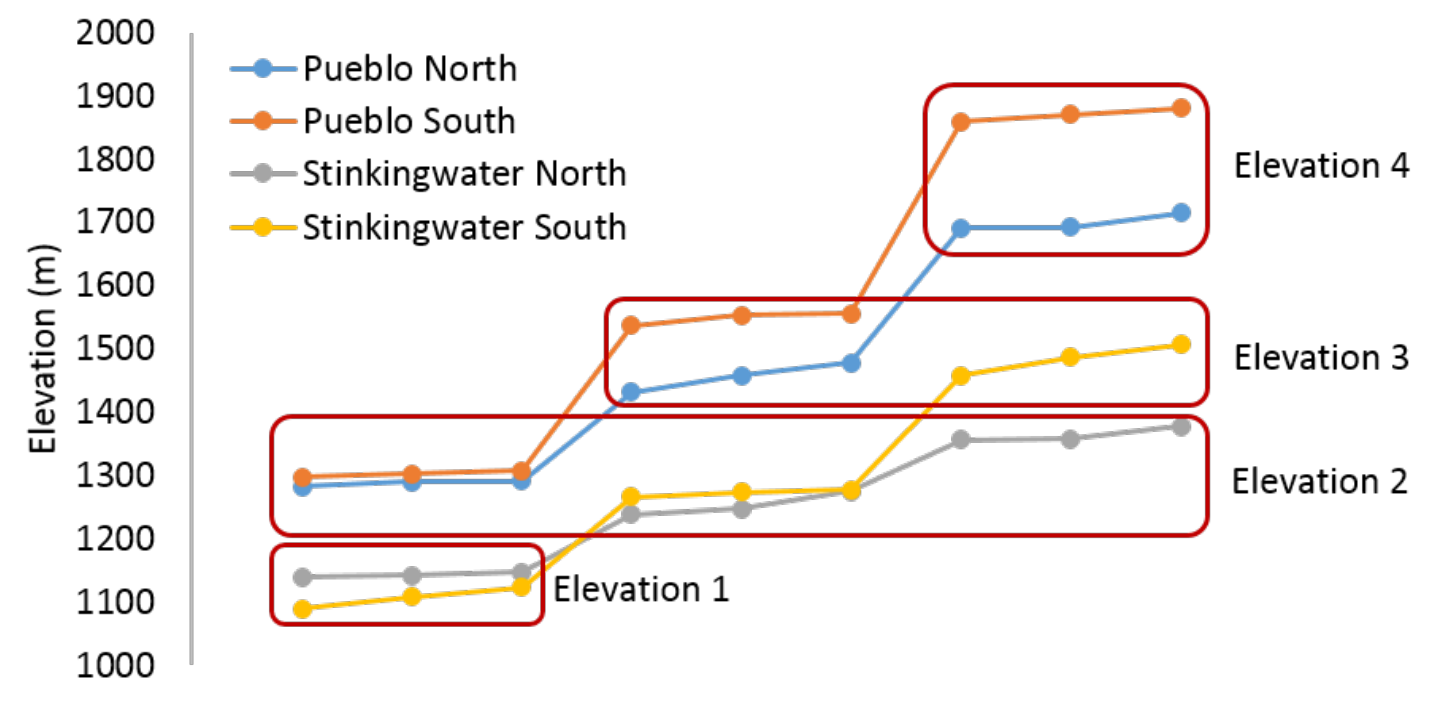

Figure 8. Graph showing sampling plots from Stinkingwater and Pueblo Mountains study areas grouped into four elevation classes. The terms North and South represent northern $(\mathrm{N})$ and southern $(\mathrm{S})$ transects within each study area. 
In Section II, Insect Community Composition, we compare 30-year averages of climate variables and interannual weather fluxes from 2012 and 2013 to insect community composition along elevation gradients at the Stinkingwater and Pueblo Mountains study areas. We used non-parametric multiplicative regression (NPMR) to measure relationships between 30-year averages of climate variables and elevation at both study areas. For all of our NMRP analyses, the neighborhood size was held at 5 percent of the sample size. We included predictors that improved model fit to the response data (represented by $\mathrm{xR}^{2}$ ) by at least 1 percent. We used PerMANOVA to compare insect community and guild richness among elevations. We explored associations between insect richness and long-term climate variables and interannual weather fluxes using NPMR and our Chao 1 estimates of richness. For Section II, Insect Community Composition, questions 1 and 2, richness was calculated using the entire 2012 dataset, including insects captured in flight and pitfall traps. For question 3, richness, diversity, and evenness were calculated using insects collected in flight traps in 2012 and 2013 from June through August. Insects captured in pitfall traps and insects captured after August in 2012 were excluded from analysis in question 3 because sampling was not conducted after August in 2013 and pitfall samples were not collected at the Pueblo Mountains study area in 2013. The differences in insect community richness between samples collected in 2012 and 2013 were compared using MRPP. These differences were associated with the change in weather variables between 2012 and 2013 using NPMR. Samples from all sampling events for each analysis were pooled, and seasonal differences in richness were not considered in this section.

In Section III, Insect Phenology, we compare seasonal insect phenology in 2012 to measured weather variables from 2012. For question 1, we used blocked MRPP to measure relationships between weather and elevation within sampling events and to compare the number of insect families that emerged at each elevation. We also used MRPP to compare the timing of first and last captures of families among elevations. We used NPMR to measure associations between timing of first and last capture of insect families with measured weather. For question 2, we used non-metric multi-dimensional scaling (NMS) and MRPP to compare insect community and guild compositions among events and elevations. We used PerMANOVA to compare abundance of insects within the community and guilds among events and elevations. We used NPMR to measure associations of insects within the community and guilds with measured weather variables. 


\section{Section I. Assessment of Sampling Design}

We examined the differences in climate, weather, vegetation, and insects between the Stinkingwater and Pueblo Mountains study areas and among the four transects to assess potential biases and variation associated with our sampling design. We addressed four primary research questions:

- Question 1: Does climate vary between study areas or between transects within study areas across similar elevations?

- Question 2: Does weather vary between study areas or between transects within study areas across similar elevations?

- Question 3: Does vegetation vary between study areas or between transects within study areas across similar elevations?

- Question 4: Does the composition of insect communities vary between study areas or between transects within study areas across similar elevations?

\section{Key Findings}

Question 1: Does climate vary between study areas or between transects within study areas across similar elevations?

a) We included 30-year averages of maximum, minimum, and median daily air temperature and precipitation as our multivariate response in our MRPP analysis of climate. We found no significant difference in the 30-year averages of climate between the study areas $(\mathrm{T}=-1.12$, $\mathrm{A}=0.09, \mathrm{p}=0.12$ ) or between transects within study areas (Pueblo: $\mathrm{T}=0.66, \mathrm{~A}=-0.11, \mathrm{p}=0.73$; Stinkingwater: $\mathrm{T}=0.84, \mathrm{~A}=-0.14, \mathrm{p}=0.79$ ). More negative values of $\mathrm{T}$ indicate stronger separation among groups and more positive values of A represent more homogenous composition within groups. Values of p indicate the likelihood of a type II error and are used to determine statistical significance of analyses.

b) When we compared each weather variable separately, we found that air temperature (maximum, minimum, and median) was significantly higher at the Pueblo study area $\left(\mathrm{F}_{1,7}=16.38, \mathrm{p}=0.02\right.$; $\mathrm{F}_{1,7}=69.13$, $\mathrm{p}=0.001$; and $\mathrm{F}_{1,7}=28.54, \mathrm{p}=0.006$, respectively where $\mathrm{F}$ values indicate how far the data are dispersed from the mean; higher $\mathrm{F}$ values indicate larger dispersion and greater differences among groups). Precipitation was significantly higher at the Stinkingwater study area $\left(\mathrm{F}_{1,7}=39.58 \mathrm{p}=0.003\right)$. We found no significant differences between transects within the plots for any of the measured weather variables.

Question 2: Does weather vary between study areas or between transects within study areas across similar elevations in 2012 and 2013?

1. We included daily average air temperature, daily average ground temperature, maximum humidity, and maximum solar radiation in our MRPP analysis of weather. When we compared study areas within sampling events at plots with overlapping elevation, we found significant differences in weather $(T=-79.88, A=0.73, p<0.001)$ at the study areas. Pairwise comparisons indicate weather varied between study areas through time (that is, among sampling events) (table 2). 
Table 2. All pairwise comparisons of weather between study areas at different sampling events were significant at $p<0.001$, Stinkingwater and Pueblo Mountain study areas.

[T: represents the degree of difference between groups, in this case study areas. A more negative value of $T$ indicates stronger differences between groups. A: represents the homogeneity within groups. Larger values of A represent more homogenous groups]

\begin{tabular}{|c|c|c|c|}
\hline Year & Event & T & A \\
\hline \multirow{7}{*}{2012} & Early June & -20.28 & 0.41 \\
\cline { 2 - 4 } & Late June & -21.12 & 0.48 \\
\cline { 2 - 4 } & Early July & -22.01 & 0.50 \\
\cline { 2 - 4 } & Late July & -20.56 & 0.43 \\
\cline { 2 - 4 } & Early August & -12.79 & 0.21 \\
\cline { 2 - 4 } & Late August & -6.84 & 0.11 \\
\cline { 2 - 4 } & September & -17.58 & 0.33 \\
\cline { 2 - 4 } & October & -19.88 & 0.43 \\
\hline \multirow{4}{*}{2013} & Late May & -10.65 & 0.59 \\
\cline { 2 - 4 } & Early June & -7.60 & 0.33 \\
\cline { 2 - 4 } & Late June & -5.83 & 0.26 \\
\cline { 2 - 4 } & Early July & -7.26 & 0.32 \\
\cline { 2 - 4 } & Late July & -7.99 & 0.38 \\
\cline { 2 - 4 } & Early August & -6.62 & 0.30 \\
\hline
\end{tabular}

2. When we compared each measured weather variable separately between study areas within events, we found significant differences in all of the variables (average daily ground temperature: $F_{27,236}=61.56, p<0.001$; average daily air temperature: $F_{27,236}=340.26, p<0.001$; daily maximum humidity: $\mathrm{F}_{27,236}=125.82, \mathrm{p}<0.001$; and daily maximum solar radiation: $\mathrm{F}_{27,236}=208.01, \mathrm{p}<0.001$ ). Pairwise comparisons of least squared means indicate that air temperature was significantly higher at the Pueblo study area during the entire season in 2012 and in the early season in 2013. Ground temperature, however, was only significantly different between study areas during one sampling event. The ground temperature was significantly higher at the Pueblo study area in early June 2013 (Stinkingwater: $24.37^{\circ} \mathrm{C}$, Pueblo: $30.78^{\circ} \mathrm{C}$, $\mathrm{p}=0.002$ ). The Pueblo study area also had significantly lower humidity and higher solar radiation during most sampling periods. This pattern was flipped once, in early June 2013, when the humidity at the Stinkingwater study area dropped below that at the Pueblo study area (table 3). 
Table 3. Pairwise comparisons of least squares means at all sampling events, Stinkingwater and Pueblo Mountain study areas, Oregon, 2012 and 2013. $t=$ test statistic that compares the observed data to what would be expected under a null hypothesis, $p=$ the likelihood of a type $I I$ error. These are used to determine statistical significance of analyses.

\begin{tabular}{|c|c|c|c|c|c|c|c|c|c|c|c|c|c|}
\hline \multirow[b]{2}{*}{ Year } & \multirow[b]{2}{*}{ Event } & \multicolumn{4}{|c|}{$\begin{array}{c}\text { Air temperature } \\
\text { (degrees Celsius) }\end{array}$} & \multicolumn{4}{|c|}{$\begin{array}{l}\text { Maximum humidity } \\
\text { (percent) }\end{array}$} & \multicolumn{4}{|c|}{$\begin{array}{c}\text { Solar radiation } \\
\text { (Watts per square meter) }\end{array}$} \\
\hline & & Pueblo & Stinkingwater & $t$ & $p$ & Pueblo & Stinkingwater & $t$ & $p$ & Pueblo & Stinkingwater & $t$ & $p$ \\
\hline \multirow{8}{*}{2012} & Early June & 10.79 & 10.45 & -0.66 & 1.0000 & 72.40 & 89.68 & 8.85 & $<0.0001$ & 937.92 & 784.91 & -17.05 & $<0.0001$ \\
\hline & Late June & 21.11 & 15.91 & -9.55 & $<0.0001$ & 41.50 & 65.03 & 11.87 & $<0.0001$ & 953.28 & 893.17 & -6.69 & $<0.0001$ \\
\hline & Early July & 25.01 & 19.26 & -10.22 & $<0.0001$ & 39.42 & 60.65 & 10.89 & $<0.0001$ & 943.96 & 885.90 & -6.47 & $<0.0001$ \\
\hline & Late July & 25.29 & 21.32 & -6.72 & $<0.0001$ & 38.28 & 59.22 & 10.81 & $<0.0001$ & 882.60 & 827.04 & -6.19 & $<0.0001$ \\
\hline & Early August & 25.97 & 22.96 & -4.95 & 0.0004 & 33.35 & 45.49 & 5.10 & 0.0002 & 927.29 & 846.30 & -8.92 & $<0.0001$ \\
\hline & Late August & 26.33 & 24.6 & 2.36 & 1.0000 & 43.11 & 45.32 & 0.93 & 1.0000 & 814.48 & 719.11 & -9.32 & $<0.0001$ \\
\hline & September & 19.85 & 16.88 & 5.12 & 0.0002 & 30.14 & 42.36 & 7.55 & $<0.0001$ & 814.15 & 719.11 & -10.59 & $<0.0001$ \\
\hline & October & 11.13 & 8.25 & 4.81 & 0.0008 & 64.02 & 79.95 & 8.15 & $<0.0001$ & 572.10 & 452.57 & -13.32 & $<0.0001$ \\
\hline \multirow{6}{*}{2013} & Late May & 12.98 & 9.03 & 5.31 & $<0.0001$ & 59.98 & 78.00 & 7.15 & $<0.0001$ & $1,064.37$ & 840.37 & -17.65 & $<0.0001$ \\
\hline & Early June & 24.07 & 20.08 & 5.30 & $<0.0001$ & 41.25 & 76.82 & 1.66 & 1.0000 & 934.77 & 903.29 & -2.48 & 1.0000 \\
\hline & Late June & 16.39 & 17.61 & -1.64 & 1.0000 & 63.41 & 77.22 & 4.10 & 0.0189 & 896.11 & 872.72 & -5.39 & $<0.0001$ \\
\hline & Early July & 26.59 & 26.05 & 0.72 & 1.0000 & 57.54 & 44.61 & -0.75 & 0.1000 & 913.33 & 915.83 & 0.20 & 1.0000 \\
\hline & Late July & 28.14 & 26.84 & 1.74 & 1.0000 & 23.29 & 34.37 & 3.29 & 0.4101 & 974.02 & 874.78 & -7.82 & $<0.0001$ \\
\hline & Early August & 23.15 & 21.28 & 2.51 & 1.0000 & 32.86 & 44.26 & 3.39 & 0.2934 & 903.49 & 835.53 & -5.35 & 0.0070 \\
\hline
\end{tabular}


c) Within study areas, we compared the same weather variables between sampling transects and events from 2012. We did not include 2013 in this analysis because we sampled only one transect per study area in 2013. We found significant differences at the Stinkingwater and Pueblo study areas ( $\mathrm{T}=-43.49, \mathrm{~A}=0.96, \mathrm{p}<0.0001$; and $\mathrm{T}=-38.84, \mathrm{~A}=0.71, \mathrm{p}<0.001$, respectively). Pairwise comparisons indicate that transects within study areas experienced different weather for every sampling event (table 4).

d) We found no significant differences in air temperature and few significant differences in ground temperature between transects at the Pueblo study area. Ground temperatures were significantly higher at the northern transect in early July (least squares means at northern transect: $26.45^{\circ} \mathrm{C}$ and southern transect: $\left.18.10^{\circ} \mathrm{C}, \mathrm{p}=0.0002\right)$ and significantly higher at the southern transect in October (least squares means at northern transect: $20.84^{\circ} \mathrm{C}$ and southern transect: $26.32^{\circ} \mathrm{C}, \mathrm{p}<0.0001$ ). Similarly, there were few differences in air or ground temperature between transects at the Stinkingwater study area. In late June and early August, air temperature was higher at the northern transect (least squares means at northern transect: $17.11^{\circ} \mathrm{C}$ and southern transect: $14.72^{\circ} \mathrm{C} \mathrm{p}=0.04$; and at northern transect: $24.35^{\circ} \mathrm{C}$ southern transect: $21.57^{\circ} \mathrm{C}, \mathrm{p}=0.004$, respectively). In early June ground temperatures were higher at the southern transect (least squares means at northern transect: $15.64^{\circ} \mathrm{C}$ and southern transect: $\left.17.51^{\circ} \mathrm{C}, \mathrm{p}=0.02\right)$. However, we found significant differences in solar radiation between transects in many sampling events at both study areas (table 5). We found significant differences in solar radiation between transects at both study areas during every sampling event, though these differences were not consistent between transects within the study areas.

Table 4. Multi-response permutation procedure comparisons of weather between transects at every sampling event at the Pueblo and Stinkingwater Mountain study areas, Oregon, 2012.

\begin{tabular}{|l|c|c|c|c|c|c|}
\cline { 2 - 7 } \multicolumn{1}{c|}{} & \multicolumn{3}{c|}{ Stinkingwater Mountains } & \multicolumn{3}{c|}{ Pueblo Mountains } \\
\hline \multicolumn{1}{|c|}{ Event } & $\mathbf{T}$ & $\mathbf{A}$ & $\mathbf{p}$ & $\mathbf{T}$ & $\mathbf{A}$ & $\mathbf{p}$ \\
\hline Early June & -11.6 & 0.91 & $<0.001$ & -5.19 & 0.24 & $<0.001$ \\
\hline Late June & -10.29 & 0.57 & $<0.001$ & -6.28 & 0.25 & $<0.001$ \\
\hline Early July & -11.5 & 0.83 & 0.007 & -5.03 & 0.19 & $<0.001$ \\
\hline Late July & -10.5 & 0.59 & 0.006 & -5.41 & 0.21 & $<0.001$ \\
\hline Early August & -11.36 & 0.78 & $<0.001$ & -4.43 & 0.18 & 0.002 \\
\hline Late August & -8.26 & 0.39 & 0.100 & -6.52 & 0.26 & $<0.001$ \\
\hline September & -11.34 & 0.75 & 0.012 & -5.06 & 0.22 & $<0.001$ \\
\hline October & -11.61 & 0.94 & $<0.001$ & -4.88 & 0.22 & $<0.001$ \\
\hline
\end{tabular}


Table 5. Solar radiation was significantly different between transects within Stinkingwater and Pueblo Mountain study areas, Oregon, 2012. Transects at the Stinkingwater Mountains study area were $19 \mathrm{~km}$ apart and transects at the Pueblo Mountains study area were $9 \mathrm{~km}$ apart.

\begin{tabular}{|l|l|c|c|r|c|}
\hline \multirow{4}{*}{ Study Area } & & \multicolumn{4}{|c|}{$\begin{array}{c}\text { Solar Radiation } \\
\text { (watts per square meter) }\end{array}$} \\
\cline { 2 - 6 } & \multicolumn{1}{|c|}{ Event } & Northern transect & Southern transect & \multicolumn{1}{c|}{$\mathbf{~}$} & $\mathbf{p}$ \\
\hline \multirow{4}{*}{$\begin{array}{l}\text { Stinkingwate } \\
\text { Mountains }\end{array}$} & Early June & 818.13 & 757.69 & 166.27 & $<0.0001$ \\
\cline { 2 - 6 } & Late June & 897.52 & 888.82 & 21.77 & $<0.0001$ \\
\cline { 2 - 6 } & Early July & 859.8 & 911.99 & -130.62 & $<0.0001$ \\
\cline { 2 - 6 } & Late July & 834.78 & 819.3 & 38.74 & $<0.0001$ \\
\cline { 2 - 7 } & Early August & 806.03 & 886.56 & -206.19 & $<0.0001$ \\
\cline { 2 - 7 } & Late August & 736.1 & 725.65 & 26.04 & $<0.0001$ \\
\cline { 2 - 7 } & September & 694.15 & 744.1 & -124.91 & $<0.0001$ \\
\cline { 2 - 7 } & October & 399.4 & 505.78 & -266.32 & $<0.0001$ \\
\hline \multirow{5}{*}{$\begin{array}{l}\text { Pueblo } \\
\text { Mountains }\end{array}$} & Early June & 935.43 & 1064.37 & 12.43 & $<0.0001$ \\
\cline { 2 - 7 } & Late June & 997.4 & 934.77 & -220.58 & $<0.0001$ \\
\cline { 2 - 7 } & Early July & 963.12 & 896.11 & -95.89 & $<0.0001$ \\
\cline { 2 - 7 } & Late July & 914.78 & 913.33 & -161.08 & $<0.0001$ \\
\cline { 2 - 7 } & Early August & 942.72 & 974.02 & -77.2 & $<0.0001$ \\
\cline { 2 - 7 } & Late August & 860 & 903.49 & -227.85 & $<0.0001$ \\
\cline { 2 - 7 } & September & 853.32 & 940.4 & -196.03 & $<0.0001$ \\
\cline { 2 - 7 } & October & 595.83 & 909.15 & -118.91 & $<0.0001$ \\
\hline
\end{tabular}

Question 3: Does vegetation vary between study areas or between transects within study areas across similar elevations?

a) We found significant differences in percent cover of vegetation functional groups between study areas within elevation class 2 ( $T=-9.42, A=0.16, p<0.001)$, but not class 3 $(\mathrm{T}=-0.49, \mathrm{~A}=0.02, \mathrm{p}=0.30)$. This indicates that vegetation composition was different at the study areas at lower elevations, but was more similar at higher elevations. We found no significant differences in vegetation composition between transects within study areas. 
Question 4: Does the composition of insect communities vary between study areas or between transects within study areas across similar elevations?

a) When we compared insect communities between study areas using PerMANOVA, we found that the insect community composition at the Pueblo and Stinkingwater study areas were significantly different $\left(\mathrm{F}_{1,192}=2.69, \mathrm{p}=0.05\right)$. Event also was significant in this analysis $\left(\mathrm{F}_{14,192}=8.02, \mathrm{p}<0.001\right)$. This analysis does not account for differences in elevation of the sampling plots at the study areas. Therefore, the analysis was run a second time with a subset of samples from each study area that overlapped in elevation (fig. 8). This second analysis used fewer samples, but accounted for the repeated measures (events) and controlled for elevation. We found a nearly significant difference between study areas for this analysis $\left(\mathrm{F}_{1,128}=2.26, \mathrm{p}=0.06\right)$.

b) We found that transects were significantly different from one another $\left(F_{3,196}=3.0\right.$, $\mathrm{p}<0.001$; fig. 9). Pairwise comparisons indicated that this significant relationship was driven by the southern transect at the Pueblo study area, which was significantly different from the north transect at the same study area $(\mathrm{t}=1.73, \mathrm{p}=0.006)$ and the southern transect at the Stinkingwater study area $(\mathrm{t}=2.05, \mathrm{p}<0.001)$. The significant relationship between transects was maintained when the analysis was run with a subset of plots from similar elevations $\left(\mathrm{F}_{3,112}=2.51, \mathrm{p}=0.007\right)$.

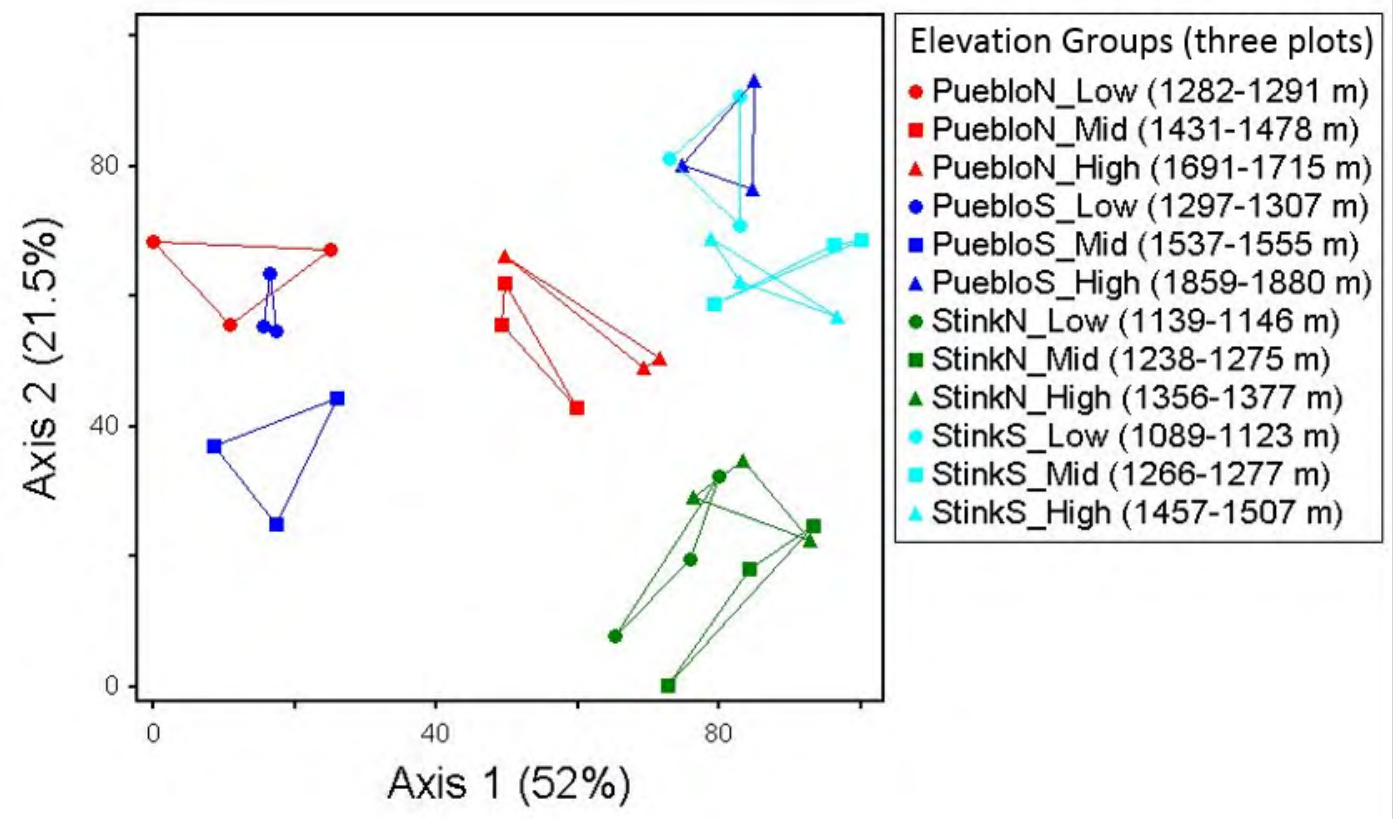

Figure 9. Non-metric multidimensional scaling analysis shows that, regardless of elevation, insect community composition at plots from the Pueblo Mountains study area were more similar to each other than to that at the plots from the Stinkingwater Mountains (Stink) study area. Insect communities at plots within a transect (indicated by PuebloN, PuebloS, StinkN, StinkS) were also more similar to each other than to other transects, with a few exceptions. Plots from the highest elevation cluster at the Pueblo study area were most similar to plots from the lowest elevation cluster at the Stinkingwater Mountains study area. 


\section{Interpretation}

Although climate was not significantly different between the study areas, the Pueblo study area is consistently hotter and drier than the Stinkingwater study area, and this trend persisted during 2012 and 2013. Vegetation was significantly different between the study areas at the low elevation plots. These differences may be influenced by differences in land use at the low plots because low elevation areas are often more accessible and, therefore, more heavily used for cattle grazing and recreation. It also could be affected by slope, which has been shown to change heatload and direct radiation (McCune, 2007). Insect community composition differed both between study areas and between transects within study areas. These differences represent variability in the system associated with biotic and abiotic habitat characters. 


\section{Section II. Insect Community Composition}

We examined relationships between insects and climate at three levels of biological organization: entire insect community, insects organized by guilds, and insect pollinators grouped by order. We addressed three primary research questions:

- Question 1: How do climate and vegetation vary along elevation gradients?

- Question 2: How do insect communities vary in relation to climate and vegetation?

- Question 3: How do interannual fluctuations in weather affect insect composition and how do these relationships compare to long-term relationships between insects and climate?

We predicted that plots at high elevations would have cooler temperatures and high annual precipitation. This would directly cause differences in the composition of vegetation and insect communities at the plots. In addition to climate, we predicted that vegetation composition would directly affect the composition of insect communities (fig. 10). We expected that long-term climate variables would have the greatest influence on the richness of insect communities and that short-term weather variables would more strongly affect diversity and evenness indices, because they are dependent on abundance as well as richness.

We captured 59,517 insects from 176 families and 10 orders at the Pueblo study area and 112,305 insects from 185 families and 11 orders at the Stinkingwater study area in 2012 and 2013. Of all the individuals captured at the Stinkingwater study area, 77,688 were from the family Cecidomyiidae (Diptera, gall gnats).

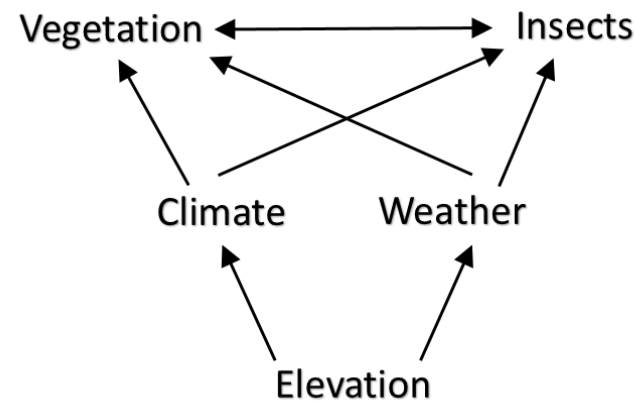

Figure 10. A depiction of the predicted relationships among elevation, climate, weather, vegetation, and insects. We predicted that elevation would affect both climate and weather. We expected that vegetation and insect community compositions would be associated with changes in climate and weather and that insect communities would also vary in association with changes in vegetation composition. 


\section{Key Findings}

Question 1: How do climate and vegetation vary along elevation gradients?

The 30-year average air temperature during the active season (May-September) decreased with elevation and the 30-year average cumulative annual precipitation increased with elevation at our study plots (fig. 11). Differences in air temperature are most likely to affect insects during the active season, because they spend their inactive season in diapause, which allows them to avoid extreme temperatures. However, cumulative annual precipitation is a good measure of response to moisture, because inactive season precipitation directly affects active season moisture availability through snowpack. Most climate variables measured were associated with elevation in the NPMR analysis, although the strengths of the relationships varied (table 6). The strongest relationships were between the standard deviation (hereinafter, variability) in average daily air temperatures (daily maximum, daily minimum, and median air temperatures) and elevation, with $\mathrm{xR}^{2}$ values greater than 0.90 . The fit of a model to the dataset can be described by $\mathrm{xR}^{2}$ and can be interpreted similarly to $\mathrm{R}^{2}$ values in a linear regression. However, the $\mathrm{xR}^{2}$ is calculated using an iterative process of removing one datapoint at a time and estimating the value of that point based on the other data in the set. Because of the difference in how $\mathrm{xR}^{2}$ is calculated, very weak models may have negative $\mathrm{xR}^{2}$ values, which can be interpreted as 0 or no fit (McCune, 2011). The variability in average daily air temperature was lower for plots at higher elevations. The relationship between the variability of precipitation and elevation was stronger than that between average precipitation and elevation. The variability of precipitation received among years was greater for plots at higher elevations than for relatively lower plots.

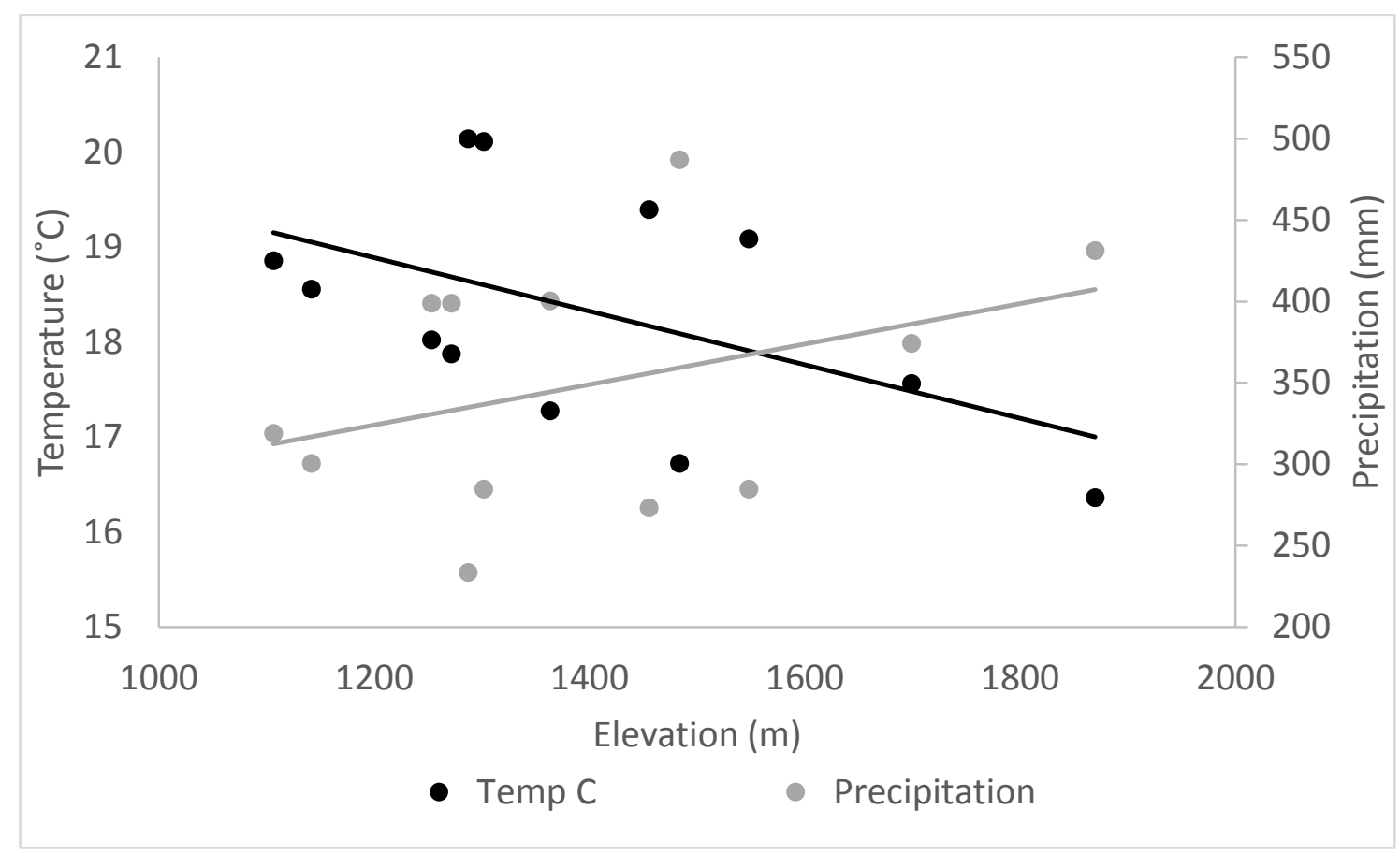

Figure 11. Linear regression analysis showing that plots at high elevations had low 30-year average air temperatures and high 30-year average precipitation, Stinkingwater and Pueblo Mountain study areas, Oregon. 
Table 6. Associations between climate and elevation indicate that the variability of air temperature among years, rather than maximum, median, or minimum air temperatures, has the strongest association with elevation at the Stinkingwater and Pueblo Mountain study areas, Oregon.

[High $\mathrm{xR}^{2}$ values indicate a strong non-linear relationship between elevation and the climate variable]

\begin{tabular}{|l|c|}
\hline \multicolumn{1}{|c|}{ Climate Variable } & $\mathbf{X R}^{\mathbf{2}}$ \\
\hline Variance of maximum daily air temperature & 0.98 \\
\hline Variance of median daily air temperature & 0.97 \\
\hline Variance of minimum daily air temperature & 0.91 \\
\hline Maximum air temperature warmest quarter & 0.68 \\
\hline Variance of minimum air temperature coldest quarter & 0.56 \\
\hline Variance of precipitation wettest quarter & 0.48 \\
\hline Variance of precipitation driest quarter & 0.45 \\
\hline Maximum daily air temperature & 0.45 \\
\hline Variance of maximum air temp warmest quarter & 0.25 \\
\hline Variance of annual precipitation & 0.23 \\
\hline Median daily air temperature & 0.20 \\
\hline Annual precipitation & 0.03 \\
\hline Minimum air temperature coldest quarter & 0.01 \\
\hline Precipitation wettest quarter & $<0.01$ \\
\hline
\end{tabular}

a) Percent cover of forbs, shrubs and invasive grasses were not associated with elevation. However, bunchgrasses had higher percent cover at higher elevations $\left(\mathrm{xR}^{2}=0.28\right)$.

b) Although most vegetation variables were not associated with elevation, they were associated with climate, particularly the variability of climate variables. Percent cover of shrubs was higher at plots with more variable precipitation among years $\left(\mathrm{xR}^{2}=0.4621\right)$. This suggests that shrubs need at least some years with higher amounts of precipitation, though they are more likely to persist through drought years than other vegetation taxa with shallower rooting systems, such as bunchgrasses. Percent cover of bunchgrasses was higher at plots with less variable high air temperatures in the summer and less variable minimum air temperatures in the winter $\left(x \mathrm{R}^{2}=0.5482\right)$. Invasive annual grasses had the highest percent cover at plots that had moderate minimum air temperatures, and low variability in precipitation during the driest season, which tended to be the drier sites at lower elevations $\left(\mathrm{xR}^{2}=0.7024\right)$. Finally, forbs had the highest percent cover at plots that had the highest variability in precipitation in the wettest and driest quarters $\left(\mathrm{xR}^{2}=0.4621\right)$. Plots with more variable climate patterns during the growing season contained more native vegetation and plots that were consistently drier contained more invasive annual grasses. 
Question 2: How do insect communities vary in relation to climate and vegetation?

a) We found no significant difference in insect community composition among elevation groups at the Pueblo study area $(\mathrm{F}=1.10, \mathrm{p}=0.320)$ but there was a significant difference at the Stinkingwater study area $(\mathrm{F}=3.41, \mathrm{p}<0.001)$. Pairwise comparisons indicate that the significant relationship was driven by differences between the highest set of plots (elevation 1,859 $\mathrm{m}$ to $1,880 \mathrm{~m}$ ) with the lowest two sets of plots $(1,282 \mathrm{~m}$ to 1,307 $\mathrm{m}$ ).

b) Insect community richness at the sampling plots was not associated with any of the climate variables measured for this study. However, guild-level analyses of insect richness indicated that the variability in climate variables among years was often more strongly related to richness of the guild than the values of the measured variables themselves (table 7). Four feeding guilds were associated with climate variables: detritivores, nectarivores, parasites, and predators (table 7). Herbivores were the only guild that was not associated with any measured environmental variable. Predator richness was higher in plots where the minimum winter air temperature was relatively moderate. Detritivore richness was highest at plots with relatively moderate variability in summer high temperatures. Nectarivore richness was higher at plots with more variability in minimum winter air temperature and more variability in precipitation. Finally, parasites had the highest richness at plots with relatively moderate variability in cold season temperatures and where precipitation was highest during the driest (and warmest) season.

c) The richness of detritivores and predators were the only guild measurements associated with vegetation (table 7). Detritivores were positively associated with shrubs and predators were negatively associated with non-native annual grasses.

Table 7. Guild-level associations between richness of insect families and environmental variables indicate that insects are associated with climate and vegetation at the Stinkingwater and Pueblo Mountain study areas, Oregon.

[High $\mathrm{xR}^{2}$ values indicate a strong non-linear relationship between feeding guild and the climate variable]

\begin{tabular}{|l|c|l|l|}
\hline \multicolumn{1}{|c|}{ Guild } & \multicolumn{1}{|c|}{$\mathrm{xR}^{2}$} & \multicolumn{1}{|c|}{ Environmental Predictor 1 } & \multicolumn{1}{c|}{ Environmental Predictor 2 } \\
\hline Detritivore & 0.0984 & $\begin{array}{c}\text { Variance of annual maximum air } \\
\text { temperature }\end{array}$ & Percent cover shrubs \\
\hline Nectarivore & 0.2249 & $\begin{array}{c}\text { Variance of daily minimum air } \\
\text { temperature }\end{array}$ & Variance of annual precipitation \\
\hline Parasite & 0.3222 & $\begin{array}{c}\text { Variance of median air temperature in the } \\
\text { coldest quarter }\end{array}$ & Precipitation in the driest quarter \\
\hline Predator & 0.2125 & Percent cover annual grass & $\begin{array}{c}\text { Minimum air temperature in the coldest } \\
\text { quarter }\end{array}$ \\
\hline
\end{tabular}


d) We captured pollinator families (nectarivores) from three orders: Diptera (flies), Hymenoptera (bees), and Lepidoptera (butterflies and moths). The richness of flies was associated with percent cover of forbs and the variability of annual extreme cold air temperatures $\left(\mathrm{xR}^{2}=0.7611\right)$. Plots with higher percent cover of forbs had greater variability in the number of nectarivorous fly families captured. Plots with high forb cover contained two nectarivorous fly families, bombylidae (bee flies) and syrphidae (hover flies). Plots with less variability in air temperatures in the winter had higher richness than plots with more moderate variability in winter air temperatures due to the addition of one family, Conopidae (thick-headed flies). Plots with higher variability in their minimum winter air temperatures and less annual grass supported higher richness of bees $\left(\mathrm{xR}^{2}=0.5843\right)$. The plots with higher annual grass cover also were less variable in the richness of bees than plots with lower annual grass cover. The richness of butterflies and moths was slightly lower and less variable at plots with higher percent cover of forbs, possibly resulting from increased competition at these plots. Richness of this group was also lower at plots with more variability in minimum cold air temperatures among years $\left(\mathrm{xR}^{2}=0.1127\right)$.

Question 3: How do interannual fluctuations in weather affect insect composition and how do these relationships compare to long-term relationships between insects and climate?

\section{Flying Insects}

a) Variation in insect composition between 2012 and 2013 was measured at all study areas for flying insects (through flight traps), but only Stinkingwater for crawling insects (through pitfall traps). We found that flying insect community composition was significantly different between sampling years at both the Stinkingwater $(\mathrm{T}=-8.56$, $\mathrm{A}=0.30, \mathrm{p}<0.001)$ and Pueblo $(\mathrm{T}=-8.51, \mathrm{~A}=0.29, \mathrm{p}<0.001)$ study areas. The insect communities at both study areas changed similarly, with a reduction in richness, diversity, and evenness from 2012 to 2013. MRPP analysis indicated that, although insect community composition at the study areas were significantly different $(T=-2.93$, $\mathrm{A}=0.05, \mathrm{p}=0.02$ ), the magnitude and direction of the change in the community compositions between years at the study areas was not significantly different $(\mathrm{T}=-0.82$, $\mathrm{A}=0.03, \mathrm{p}=0.18$ ). This indicates that flying insect community composition shifted in response to environmental factors similarly at both study areas. We found no significant difference in the composition of crawling insects between years at the Stinkingwater study area $(\mathrm{T}=-0.49, \mathrm{~A}=0.02, \mathrm{p}=0.23)$.

b) We found associations between interannual changes in weather and richness, diversity, and evenness of the flying insect community (table 8). Richness had the lowest $\mathrm{xR}^{2}$ value (0.2880), indicating that relationships between changes in richness and weather were more difficult to predict than those between changes in diversity or evenness and weather at this level of organization. 
Table 8. Community-level analyses of changes in insect richness, diversity, and evenness with changes in environmental variables between 2012 and 2013 indicate that the community is affected by interannual variability in weather and vegetation at Stinkingwater and Pueblo Mountain study areas, Oregon.

[High $\mathrm{xR}^{2}$ values indicate a strong non-linear relationship between the insect community statistic and the climate variable]

\begin{tabular}{|c|l|l|l|}
\hline Statistic & $\mathrm{XR}^{2}$ & \multicolumn{1}{|c|}{ Environmental Predictor 1 } & \multicolumn{1}{c|}{ Environmental Predictor 2 } \\
\hline Richness & 0.288 & Study area & Median daily ground temperature \\
\hline Diversity & 0.5546 & $\begin{array}{l}\text { Maximum air temperature in the } \\
\text { coldest quarter }\end{array}$ & Percent cover annual grass \\
\hline Evenness & 0.4689 & $\begin{array}{c}\text { Minimum air temperature in the coldest } \\
\text { quarter }\end{array}$ & Percent cover annual grass \\
\hline
\end{tabular}

c) Decreased richness, diversity, and evenness of the flying insect community from 2012 to 2013 were associated with changes in vegetation and weather including increased nonnative annual grass cover, decreased median ground temperatures in the active season, and variable maximum air temperatures in the winter (decreased at some plots and increased at some plots). The variability in diversity and evenness of insects among plots that had stable or increasing maximum winter air temperatures between 2012 and 2013 was much smaller than the variability of plots that had cooler cold season air temperatures in 2013. This suggests that milder (i.e. warmer) winters may benefit some families, but not others. Finally, plots that had similar ground temperatures in the active season for both years, or that were warmer in 2013 than 2012, retained more richness than plots that had cooler ground temperatures in 2013.

d) Changes in richness within guilds was more strongly associated with changes in weather than with climate (tables 7 and 9), except for nectarivores. Changes in richness of nectarivores were relatively poorly associated with changes in the measured weather variables. Evenness and diversity of predators, nectarivores, and herbivores were strongly associated with changes in weather, but this relationship was not as strong for detritivores or parasites (table 9). Differences in the strength of relationships between insect guilds and the weather and climate variables with which they were associated indicate that guild-level analyses reveal trends that are specific to life history traits associated with feeding guilds.

e) All guilds were associated with some measure of warm season temperatures, whether air or ground temperature (table 9). Three guilds, herbivore, nectarivore, and parasite, were also sensitive to temperature in the cold season, when insects are in diapause. For most guilds, plots with the greatest change in summer air temperatures experienced the greatest decreases in richness, diversity, and evenness whereas plots with the greatest change in ground temperature (during the active season) experienced the smallest losses in these measures. Most plots had colder winter air temperatures in 2013 than in 2012, but the plots that cooled less or (the few) that were warmer in 2013 retained higher richness and diversity of herbivores, nectarivores and parasites. Contrary to what we expected, richness associated more strongly with changes in environmental variables (for example, vegetation and weather) between 2012 and 2013 than richness associated with climate variables. 
f) We found that nectarivores were associated with weather variables. The associations between flies and weather variables were not as strong as those between flies and climate. The temperature variables with which flies associated were warm season variables, as opposed to the cold season variables with which they were associated in the climate analysis (table 10). However, their richness was higher at warmer plots in the warm season and lower at the colder plots in the cold season, consistently indicating a sensitivity to cold air temperatures. Bees, moths, and butterflies associated with similar climate and weather variables. As in the climate analysis, the association between the richness of moths and butterflies and weather variables was not very strong, although their diversity and evenness were more strongly associated with weather.

g) Bees, butterflies, and moths responded to interannual changes in vegetation. The evenness of butterflies and moths and the richness of bees were retained at higher levels at plots that lost fewer bunchgrasses between 2012 and 2013, although the evenness of butterflies and moths was variable among plots where there was no loss of bunchgrasses. The diversity of bees was associated with the percent cover of shrubs. Most plots gained bee diversity between years, and the plots that gained the most diversity also gained the most shrub cover. Butterflies and moths were the only order within the nectarivore guild to associate with forbs. Although moths and butterflies decreased overall between years, plots with greater increases in forb cover between years had smaller decreases in richness of moths and butterflies.

h) Flies stood out from the other two orders because they associated only with changes in summer air temperature variables, whereas bees, butterflies, and moths also associated with changes in winter air temperatures and vegetation variables. Overall, most plots lost richness, diversity, and evenness of flies between 2012 and 2013, but plots with warmer summer air temperatures (minimum, mid, and maximum) retained more richness and diversity than plots with cooler summer air temperatures. Bees, butterflies, and moths were sensitive to air temperatures during the winter. Diversity and evenness of bees increased between sampling years in response to warmer winters. Detected richness of bees, however, had U-shaped distribution where plots with little or no change in winter air temperatures lost the most richness and plots with more extreme cold or warm winters retained more richness. These results are counter-intuitive, but it is possible that lower winter temperatures indicate more consistent snow insulation for individuals buried right below the surface of the soil. Warmer winters may simply be more survivable for overwintering pupae even without snow insulation. Richness, diversity, and evenness of butterflies and moths all decreased at most plots between sampling years in response to lower median winter temperatures in 2013. However, plots that cooled less between years retained higher detected richness, diversity and evenness of moths and butterflies. 
Table 9. Guild-level analyses of the relationship between interannual changes in insect richness, diversity, and evenness and interannual changes in environmental variables at the Stinkingwater and Pueblo Mountain study areas, Oregon.

[High $\mathrm{xR}^{2}$ values indicate a strong non-linear relationship between the guild and the climate variable]

\begin{tabular}{|c|c|c|c|c|}
\hline Guild & Statistic & $\mathrm{xR}^{2}$ & Environmental Predictor 1 & Environmental Predictor 2 \\
\hline \multirow{3}{*}{ Detritivore } & Richness & 0.5992 & Annual daily max ground temperature & Daily median ground temperature \\
\hline & Diversity & 0.3943 & Elevation & Daily minimum air temperature in the warmest quarter \\
\hline & Evenness & 0.3538 & Elevation & Percent cover bunchgrass \\
\hline \multirow{3}{*}{ Herbivore } & Richness & 0.8076 & Study area & Daily minimum air temperature in the coldest quarter \\
\hline & Diversity & 0.7929 & Daily maximum ground temperature & Percent cover shrubs \\
\hline & Evenness & 0.6979 & Annual grass & Percent cover shrubs \\
\hline \multirow{3}{*}{ Nectarivore } & Richness & 0.2299 & Daily max air temperature in the warmest quarter & Percent cover forbs \\
\hline & Diversity & 0.7701 & Elevation & Daily median air temperature in the coldest quarter \\
\hline & Evenness & 0.797 & Elevation & Daily minimum air temperature in the warmest quarter \\
\hline \multirow{3}{*}{ Parasite } & Richness & 0.7319 & Daily median air temperature in the coldest quarter & Percent cover annual grass \\
\hline & Diversity & 0.1404 & Daily minimum air temperature in the warmest quarter & Percent cover bunchgrass \\
\hline & Evenness & 0.0691 & Daily median air temperature in the coldest quarter & Daily median air temperature in the warmest quarter \\
\hline \multirow{3}{*}{ Predator } & Richness & 0.6776 & Daily median air temperature in the warmest quarter & Daily median ground temperature \\
\hline & Diversity & 0.6228 & Daily max ground temperature & Percent cover bunchgrass \\
\hline & Evenness & 0.7759 & Daily minimum air temperature in the warmest quarter & Percent cover bunchgrass \\
\hline
\end{tabular}


Table 10. Analyses of orders within the nectarivore guild indicate that pollinators from different orders are sensitive to changes in different weather and vegetation variables. Stinkingwater and Pueblo Mountain study areas, Oregon.

[High $\mathrm{xR}^{2}$ values indicate a strong non-linear relationship between the order and the climate variable]

\begin{tabular}{|c|l|l|l|l|}
\hline Order & Statistic & \multicolumn{1}{|c|}{$\mathbf{x R}^{2}$} & \multicolumn{1}{|c|}{ Environmental Predictor 1 } & \multicolumn{1}{|c|}{ Environmental Predictor 2 } \\
\hline \multirow{4}{*}{ Diptera } & Richness & 0.106 & Daily maximum air temperature in the warmest quarter & Daily median air temperature in the warmest quarter \\
\cline { 2 - 6 } & Diversity & 0.281 & Daily minimum air temperature in the warmest quarter & Daily maximum ground temperature \\
\cline { 2 - 6 } & Evenness & 0.2908 & Study area & Daily median ground temperature \\
\hline \multirow{4}{*}{ Hymenoptera } & Richness & 1 & Daily maximum air temperature in the coldest quarter & Percent cover bunchgrass \\
\cline { 2 - 6 } & Diversity & 0.5212 & Daily median air temperature in the coldest quarter & Percent cover shrub \\
\cline { 2 - 6 } & Evenness & 0.7609 & Daily median air temperature in the coldest quarter & Daily minimum ground temperature \\
\hline \multirow{3}{*}{ Lepidoptera } & Richness & 0.1966 & Daily median air temperature in the coldest quarter & Percent cover forbs \\
\cline { 2 - 6 } & Diversity & 0.5112 & Daily median air temperature in the coldest quarter & Daily minimum ground temperature \\
\cline { 2 - 6 } & Evenness & 0.5594 & Daily median air temperature in the coldest quarter & Percent cover bunchgrass \\
\hline
\end{tabular}




\section{Interpretation}

Variability in Climate, Weather, and Habitat Affected Richness, Diversity, and Evenness of Insect Communities

We found evidence that climate affected insect community composition and structure at the scale of this study. We found that air temperature variability, rather than long-term average air temperature, was most often associated with insect community composition. The relationship between precipitation and elevation was weak, indicating that there may not have been enough variability in elevation to detect relationships between precipitation and insects. We only detected a relationship between parasites and the 30 -year average of precipitation. It is possible that a greater change in elevation between sampling plots would have revealed more relationships because insect populations may contain enough genetic plasticity to accommodate elevational differences in temperature through altered body color and size, wing formation, fecundity, or timing of life history traits (Hodkinson, 2005). Changes in body size along elevation gradients may decrease metabolic costs (Buckley and others, 2013).

At the scale of this study, insect communities appeared to be more strongly influenced by weather than climate. Our results suggest that interannual variation in weather, especially air temperature, limit the distribution of insects. Insect species are often limited by the amount of thermal energy they need to complete development within their active season (Bird and Hodkinson, 1999; Hodkinson, 2005). Unpredictable swings in air temperature may limit the distribution of some insect groups by limiting the ability of juveniles to successfully survive to adulthood in years with low air temperatures.

\section{Effects on Pollinators}

Insect pollinator assemblages have been shown to change along elevation gradients in response to changes in climate and vegetation. Species compositions tend to move from bee-dominated at lower elevations and fly-dominated at higher elevations (Kearns, 1992; Arnold and others, 2009), at least partially in response to differences in humidity (Devoto and others, 2005).

Although bees have been shown to dominate relatively dry habitat compared to flies, our analyses indicate that bees have lower family richness where invasive annual grasses are more abundant, which tend to be lower elevation, dry plots (Knutson and others, 2014). Fly pollinators at higher elevations may compete with bees, which could limit the range of some bees along elevation gradients (Kearns, 1992). Increased intensity and frequency of disturbance events, such as fire, have been shown to increase the spread of invasive annual grasses at drier, lower elevation areas of the Great Basin (Balch and others, 2013). This disturbance may reduce and fragment habitat and reduce habitat quality for bee pollinators in this system.

\section{Invasive Annual Grasses Affected the Distribution of Insects Among Plots}

Land use change and invasive species interact with changing climate to increase the effects of natural stressors on communities and change disturbance regimes. These changes may be as important as or more important than the direct effect of change in climate variables in predicting ecosystem response to climate change (Dunne and others, 2004). We found evidence of the effect of invasive annual grasses on insects at every level of analysis. By replacing native vegetation, non-native annual grasses may exacerbate habitat fragmentation that could lead to reduced foraging success for bees or hunting success for predators. 


\section{Section III. Insect Phenology}

The goal of this part of the study was to document phenological shifts in insect communities in response to temperature along elevation gradients. We examined the following questions:

- Question 1: How is the timing of insect emergence or diapause related to variability in weather along an elevation gradient at the beginning and end of the active season?

- Question 2: How does insect abundance vary through time in relation to environmental characteristics, such as air and ground temperature, growing degree days, relative humidity, and solar radiation?

We predicted that insects emerge later at higher elevations due to lower springtime temperatures and, therefore, have shorter annual activity periods than insects at lower elevations.

\section{Key Findings}

Question 1: How is the timing of insect emergence or diapause related to variability in weather along an elevation gradient at the beginning and end of the active season?

a) Weather was significantly variable among elevations within sampling events as indicated by blocked MRPP analyses ( $\mathrm{T}=-13.041, \mathrm{~A}=0.021, \mathrm{p}<0.0001)$. We measured cumulative growing degree days (formula 1) and maximum humidity at the plots and found that they were significantly different among elevations within sampling events $(T=-9.491 \mathrm{~A}=0.016 \mathrm{p}<0.0001$ and $\mathrm{T}=-21.401 \mathrm{~A}=0.199 \mathrm{p}<0.0001$, respectively).

b) We compared the number of families that were captured for the first time at each elevation. We found significantly more families were captured for the first time at lower elevations in both years (2012: $T=-40.36, A=0.08, p<0.001 ; 2013$ : $T=-9.91, A=0.04, p<0.001$; fig.12). Similarly, significantly more families were captured for the last time at lower elevations in 2012 ( $\mathrm{T}=-6.37$, $A=0.01, p<0.001 ; 2013$, fig. 12). However, we found that, throughout the entire sampling season in 2012, more insect families were captured at higher elevations at the Pueblo $\left(\mathrm{F}_{5,17}=20.37\right.$, $\mathrm{p}<0.001)$ and Stinkingwater $\left(\mathrm{F}_{5,17}=4.17, \mathrm{p}=0.02\right)$ study areas. 
First Captures 2012

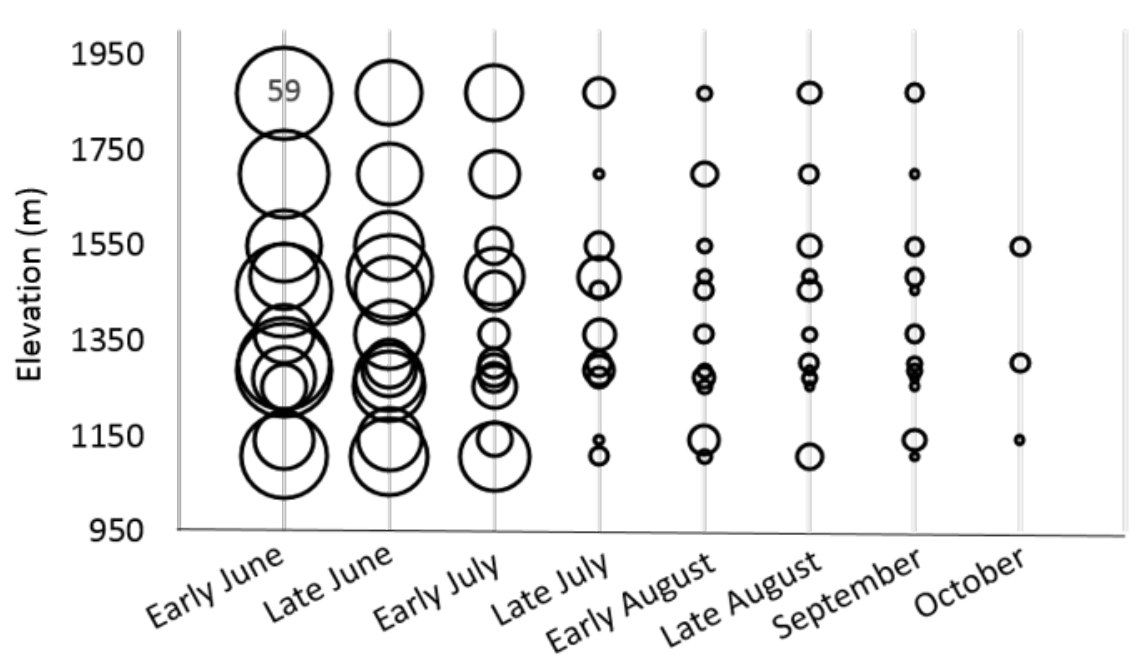

Last captures 2012

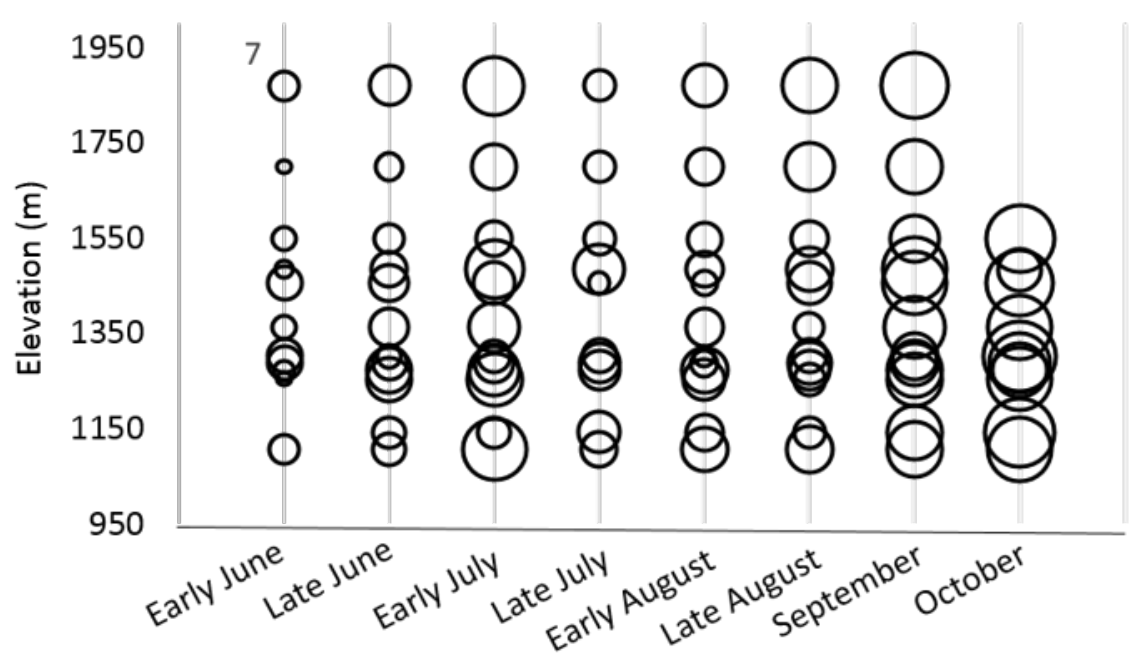

Figure 12. Bubble graph showing the number of insect families captured for the first time or the last time at each sampling elevation and at what time during the season they were captured, Stinkingwater and Pueblo Mountains, Oregon. The size of the bubbles represents the number of families captured and are scaled relative to each other. As a point of reference, the bubble in the top left corner of each panel is labeled with the number of families that it represents. Most families were captured for the first time early in the sampling season at relatively low elevations. Though the relationship was not as dramatic, most families were captured for the last time at relatively low elevations late in the season, often in September or October, 2012. 
c) We found that timing of first capture was significantly different among elevations for every feeding guild in 2012 (table 11). Time of first capture was later at higher elevations for every guild except detritivores, which emerged earlier at higher elevations in 2012 (fig. 13). Timing of last capture was significantly different among elevations for herbivores, predators and parasites in 2012 (table 11). We did not measure last capture in 2013, because our sampling was truncated to focus on the early part of the season.

d) We found strong correlations between the timing of first capture of insects from feeding guilds with weather variables in 2012 (table 12; fig. 13). Minimum ground temperature, humidity, solar radiation, and growing degree days were the most important variables that we measured in 2012.

Table 11. Multi-response permutation procedure analysis indicates differences in timing of first and last captures of families within feeding guilds among elevations in 2012.

[T: represents the separation between groups, the more negative $\mathrm{T}$, the greater the separation. A: represents the homogeneity within groups, a larger value of A represents a group that is more homogenous, $\mathrm{p}=$ the likelihood of a type II error]

\begin{tabular}{|c|c|c|c|c|c|}
\hline \multicolumn{6}{|c|}{ First Capture } \\
\hline \multirow{6}{*}{2012} & Guild & $\mathbf{T}$ & A & $\mathbf{p}$ & $\mathrm{n}$ \\
\hline & Herbivore & -15.91 & 0.096 & $<0.0001$ & 461 \\
\hline & Detritivore & -4.03 & 0.114 & 0.0007 & 101 \\
\hline & Nectarivore & -9.77 & 0.092 & $<0.0001$ & 295 \\
\hline & Predator & -3.84 & 0 & 0.0012 & 237 \\
\hline & Parasite & -5.85 & 0.1 & $<0.0001$ & 261 \\
\hline \multicolumn{6}{|c|}{ Last Capture } \\
\hline \multirow{6}{*}{2012} & Guild & $T$ & A & $p$ & $\mathrm{n}$ \\
\hline & Herbivore & -3.102 & 0.036 & 0.0089 & 192 \\
\hline & Detritivore & 1.306 & 0.08 & 0.133 & 33 \\
\hline & Nectarivore & 0.2349 & 0.006 & 0.348 & 96 \\
\hline & Predator & 1.173 & 0.064 & 0.029 & 83 \\
\hline & Parasite & -1.3309 & 0.039 & 0.034 & 118 \\
\hline
\end{tabular}




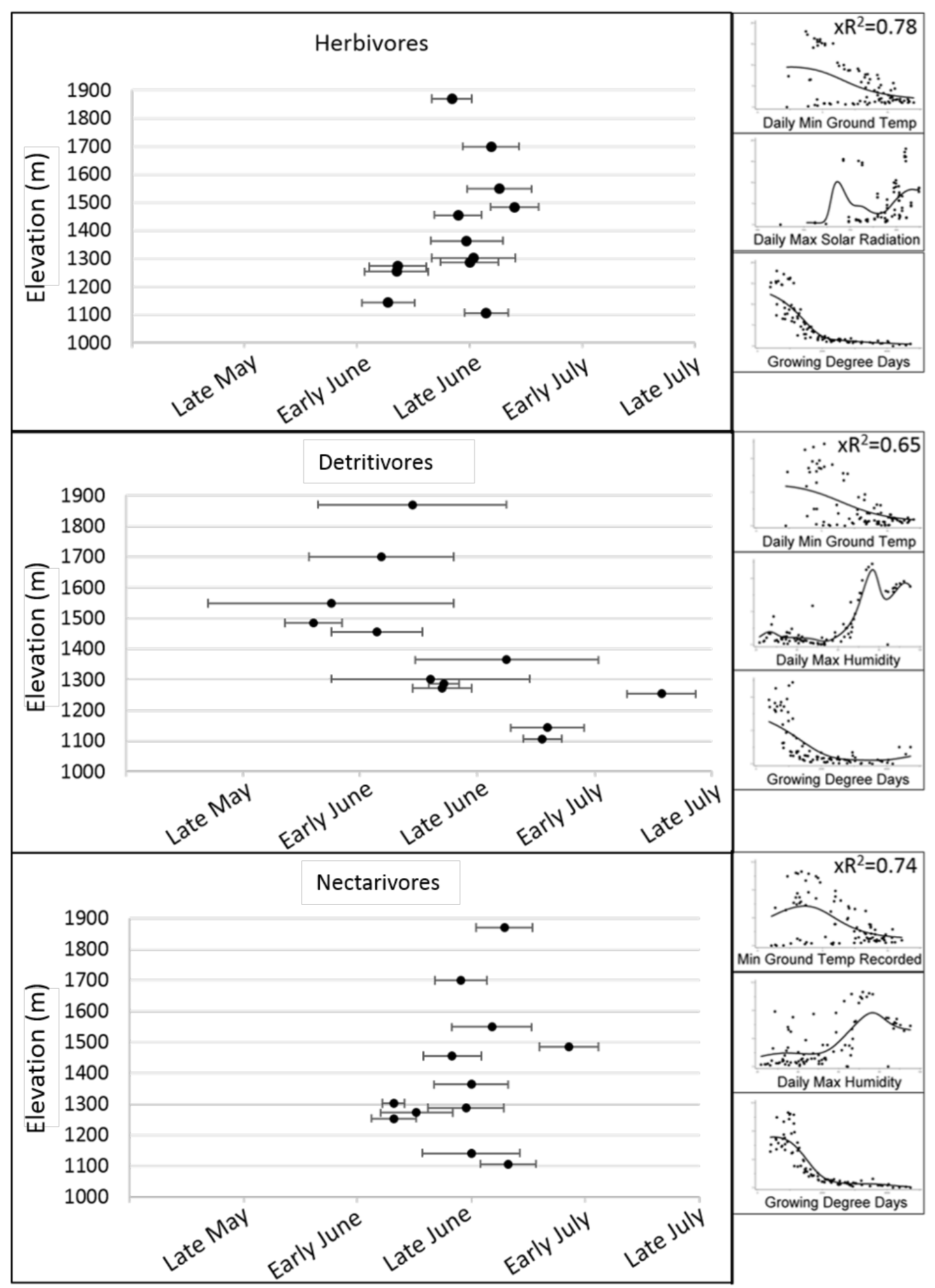

Figure 13. Average timing of first capture for all families grouped by feeding guilds was significantly different among elevations in 2012 (large windows, table 11), Stinkingwater and Pueblo Mountains, Oregon. Weather variables measured along elevation gradients indicated that timing of first capture was strongly associated with measured weather variables for all feeding guilds (small windows, table 12). The Y-axis of the small window plots (showing weather associations) represents the number of families within the guild that were captured for the first time in any sample. 


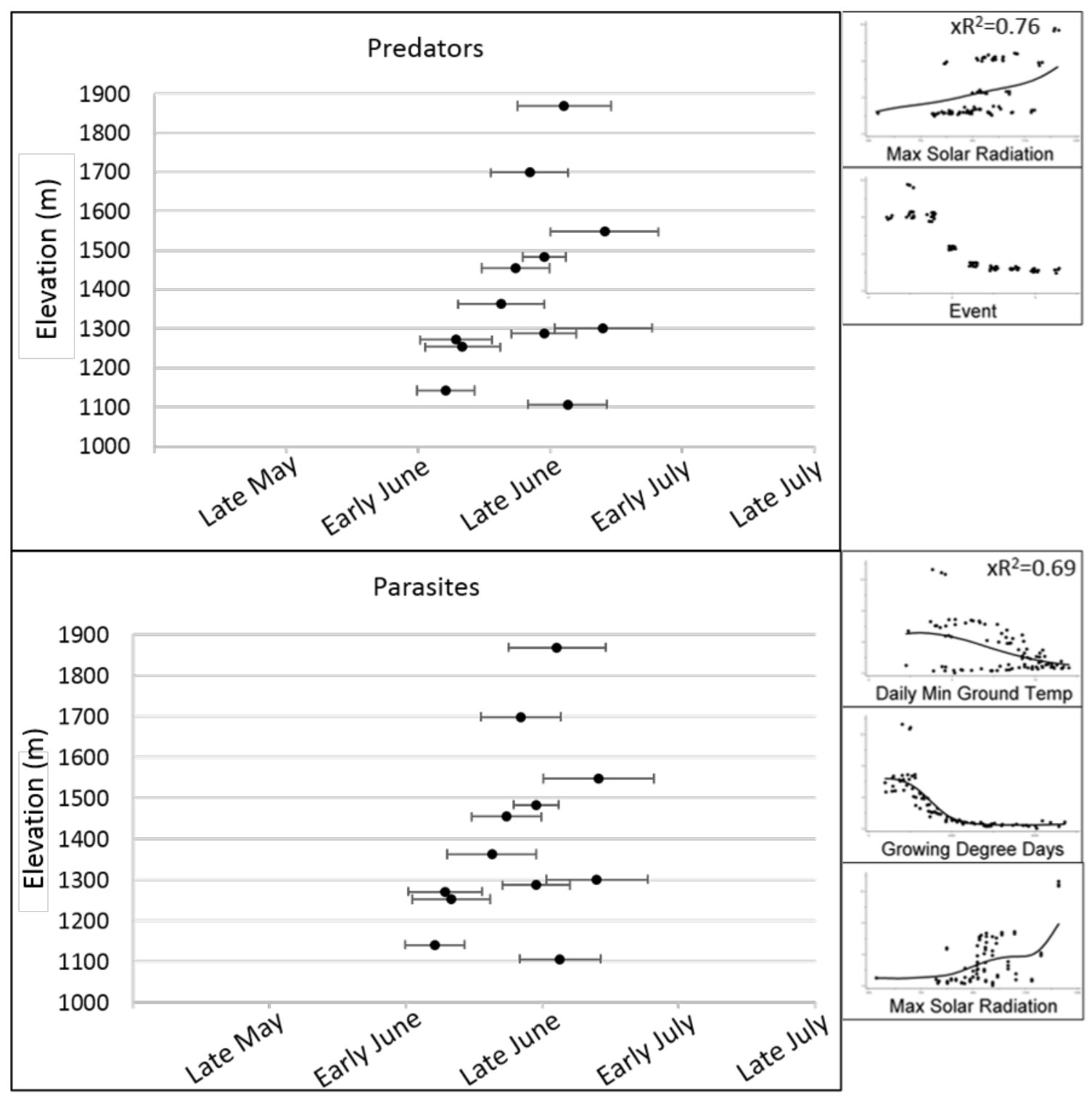

Figure 13.-Continued 
Table 12. Timing of first and last capture of insect families within guilds was strongly associated with measured weather variables at the Stinkingwater and Pueblo Mountain study areas, Oregon. In this analysis, some guilds were best explained by three predictor variables while others were best explained by two predictor variables.

[High $\mathrm{xR}^{2}$ values indicate a strong non-linear relationship between feeding guild and the climate variable]

\begin{tabular}{|c|c|c|c|c|c|}
\hline \multicolumn{6}{|c|}{ First Capture } \\
\hline \multirow{6}{*}{2012} & Guild & $x R^{2}$ & Environmental predictor 1 & Environmental predictor 2 & Environmental predictor 3 \\
\hline & Detritivore & 0.6509 & Daily minimum ground temperature & Daily maximum humidity & Growing degree days \\
\hline & Herbivore & 0.7845 & Daily minimum ground temperature & Daily maximum solar radiation & Growing degree days \\
\hline & Nectarivore & 0.7418 & Minimum ground temperature recorded & Daily maximum humidity & Growing degree days \\
\hline & Parasite & 0.6781 & Daily minimum ground temperature & Maximum solar radiation recorded & Growing degree days \\
\hline & Predator & 0.7551 & Event & Maximum solar radiation recorded & \\
\hline \multicolumn{6}{|c|}{ Last Capture } \\
\hline \multirow{6}{*}{2012} & Guild & $\mathrm{XR}^{2}$ & Environmental predictor 1 & Environmental predictor 2 & Environmental predictor 3 \\
\hline & Detritivore & 0.0966 & Minimum air temperature on coldest day & Maximum humidity on most humid day & \\
\hline & Herbivore & 0.6517 & Event & Daily maximum ground temperature & \\
\hline & Nectarivore & 0.5969 & Event & Daily maximum humidity & \\
\hline & Parasite & 0.1961 & Daily maximum solar radiation & Minimum day length & \\
\hline & Predator & 0.6017 & Event & Growing degree days & \\
\hline
\end{tabular}


Question 2: How does insect abundance vary through time in relation to environmental characteristics, such as air and ground temperature, relative humidity, and solar radiation?

a) Measured weather (air temperature, ground temperature, humidity, and solar radiation) differed among sampling events, and among elevations within events (table 13, $\mathrm{p}<0.001$ for all analyses). In both years, MRPP values of T were more negative and values of A were larger for samples grouped by event, indicating that these groups were more separated from each other and more homogenous in composition than groups defined by elevation within events. The mean difference between maximum air temperatures among the lowest and highest elevations within events on each transect was $8.72 \pm 0.49^{\circ} \mathrm{C}$ in 2012 and $6.95 \pm 2.69^{\circ} \mathrm{C}$ in 2013 . The mean difference between the highest and lowest maximum air temperatures at a single elevation among the warmest and coolest sampling events was $25.17 \pm 1.70^{\circ} \mathrm{C}$ in 2012 and $24.52 \pm 2.16^{\circ} \mathrm{C}$ in 2013.

b) Insect composition varied significantly among elevations within events ( $T=-21.364, A=0.290$, $\mathrm{p}>0.001)$ and among events ( $\mathrm{T}=-49.684, \mathrm{~A}=0.152$, $\mathrm{p}>0.001$; figs. 14 and 15) in 2012 on the basis of MRPP and NMS.

c) We compared the timing of peak abundance for all families that were captured at every sampling event, and found that the timing of peak abundance for the most abundant insect families was staggered throughout the season (fig. 15).

d) As in Section II. Insect Community Composition, we grouped insect families into feeding guilds for analysis. Herbivores and nectarivores were the most abundant insect guilds captured throughout the sampling season in both years. Both of these guilds peaked in abundance in the early part of the season, though herbivores also had a second larger peak at the end of the season (fig. 16).

Table 13. Multi-response permutation procedure analysis was used to compare weather among sampling events and among elevations nested within sampling events at our plots located at the Stinkingwater and Pueblo Mountains, Oregon. In 2012 and 2013, there were significant differences among plots measured repeatedly (events) and plots measured during the same events along an elevation gradient ( $p<0.0001$ for all analyses).

[T: represents the separation between groups, the more negative $\mathrm{T}$, the greater the separation. A: represents the homogeneity within groups, a larger value of A represents a group that is more homogenous, $\mathrm{p}=$ the likelihood of a type II error]

\begin{tabular}{|c|c|c|l|}
\hline Year & T & A & \multicolumn{1}{c|}{ Group } \\
\hline \multirow{2}{*}{2013} & -28.93 & 0.410 & Event \\
\cline { 2 - 4 } & -12.81 & 0.302 & Elevation within event \\
\hline \multirow{2}{*}{2012} & -86.65 & 0.579 & Event \\
\cline { 2 - 4 } & -32.06 & 0.485 & Elevation within event \\
\hline
\end{tabular}




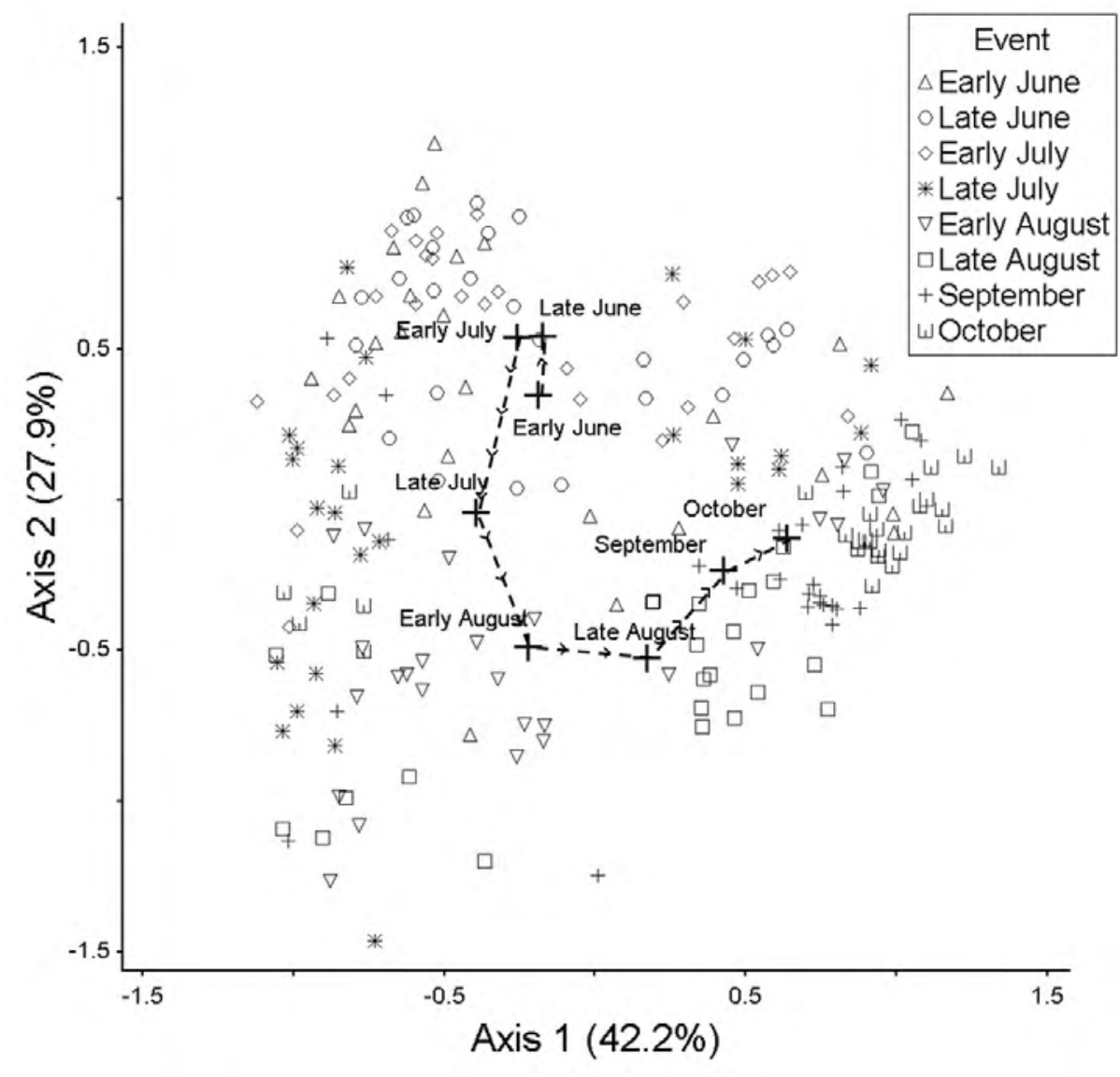

Figure 14. Non-metric multidimensional scaling showing that insect samples from different events during the sampling season changed somewhat systematically, with the mean value for each month shifting through ordination space. 


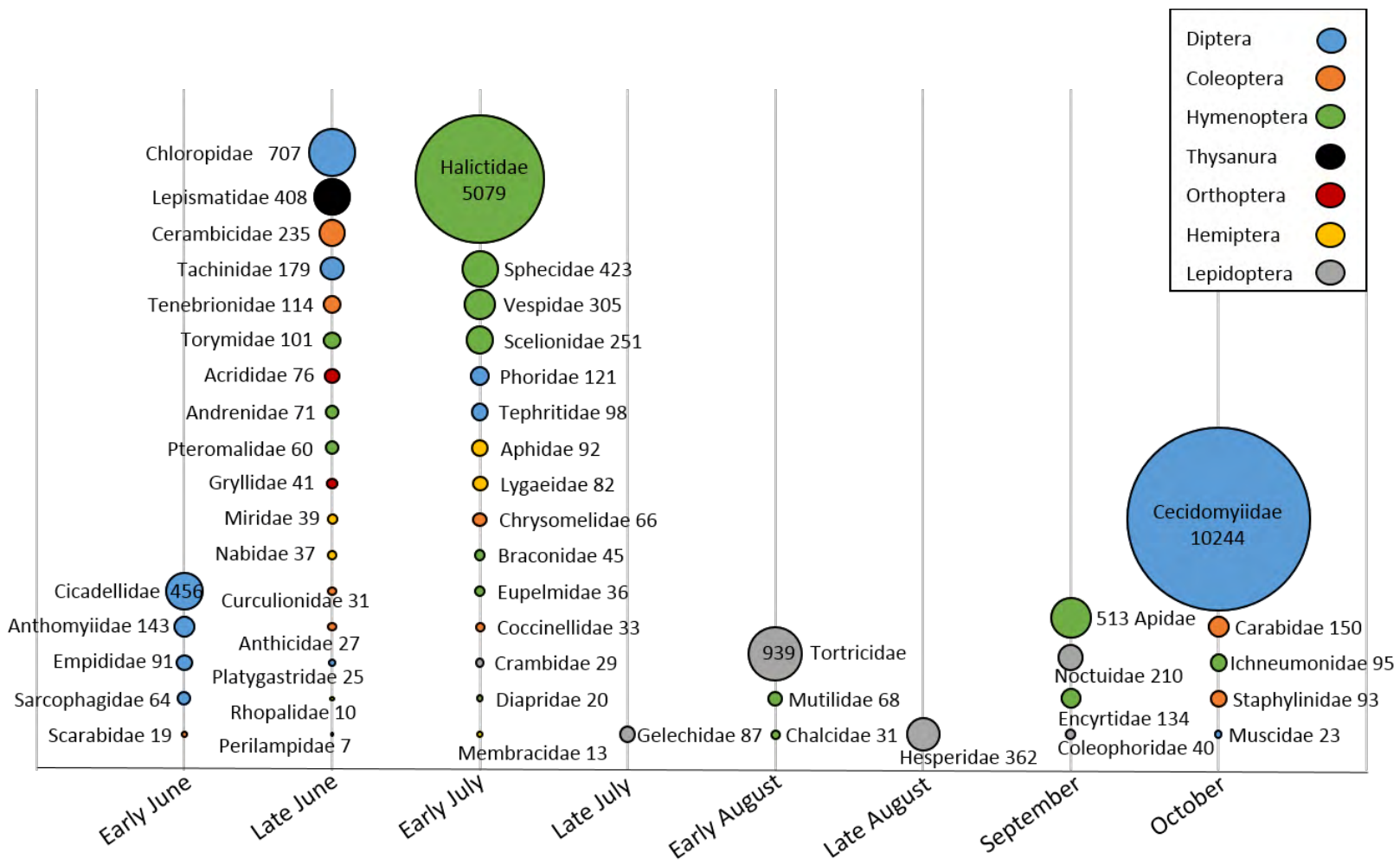

Figure 15. Peak abundance of families captured during every sampling event, Stinkingwater and Pueblo Mountains, Oregon. The sizes of the bubbles represent the relative abundance of the families at peak abundance. The bubbles are also labeled with the number of individuals they represent. The bubbles are colored coded by order.

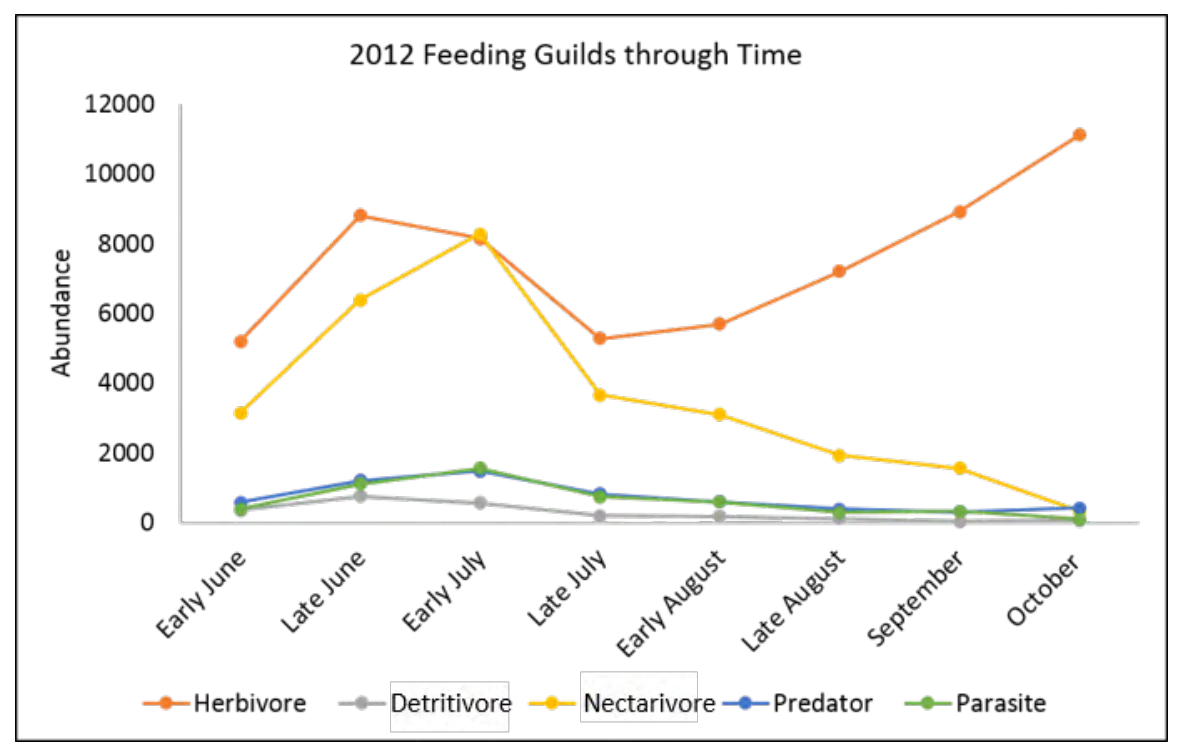

Figure 16. Abundances of insects by feeding guilds throughout the sampling season in 2012. All feeding guilds peaked in abundance in June and July in 2012, but herbivores and nectarivores were by far the most frequently captured insects. Herbivores had a second peak in October. 
d) We found that the composition of insect guilds varied significantly by sampling event and by elevations within sampling events, indicating that seasonal variability in weather at plots and differences in weather among plots associated with elevation affected the composition of insect guilds (table 14). Two guilds, herbivores and predators, varied in abundance among elevations within events (fig. 17).

f) We used NPMR to associate changes in weather resulting from event and elevation to the abundance of insect guilds. We included event and elevation as predictors in the model to represent variability that was not explained by the measured weather variables. Minimum air temperature and elevation explained 32.4 percent of the variance in the abundance of detritivores among samples, the highest $\mathrm{xR}^{2}$ value achieved for any guild in this analysis (table 15). Samples from high elevations with higher minimum air temperatures (probably from warmer sampling events) contained fewer detritivores. The abundance of predators was also relatively well predicted by elevation and maximum humidity with 31.4 percent of the variance explained. In this case, plots and events with higher humidity had higher abundances and plots at higher elevation had slightly lower abundances. Parasites were most strongly associated with temperature, ground and air temperatures explained 18.4 percent of the variability in this group. We captured slightly fewer parasites at plots and events with higher temperatures. The variability in abundance of herbivores and nectarivores was not well explained by our model, 6.2 and 8.4 percent, respectively.

g) Within the nectarivore guild, bees were the most abundant pollinators, especially in June and early July (fig. 18). In August, butterflies and moths became more abundant than bees, but their overall abundance throughout the season was lower. When we compared the abundance of insect orders within the nectarivore guild using PerMANOVA, we found that, as in the guild-level analysis, all orders within the nectarivore guild varied significantly in composition among events and elevations within events (table 16). Unlike the guild-level analysis, we found that the abundance of all of the orders also changed significantly among events and elevation within events (table 16).

Table 14. Composition of insect guilds was significantly different among sampling events and elevations within events.

[ $\mathrm{F}=$ the magnitude of differences among groups, $\mathrm{p}=$ the likelihood of a type II error]

\begin{tabular}{|l|c|c|c|c|}
\hline & \multicolumn{2}{|c|}{ Elevation } & \multicolumn{2}{c|}{ Event } \\
\hline \multicolumn{1}{|c|}{ Guild } & $\mathbf{F}$ & $\boldsymbol{p}$ & $\mathbf{F}$ & $\boldsymbol{p}$ \\
\hline Detritivore & 2.569 & 0.0002 & 8.679 & 0.0002 \\
\hline Nectarivore & 3.349 & 0.0002 & 19.251 & 0.0002 \\
\hline Predator & 2.218 & 0.0002 & 8.388 & 0.0002 \\
\hline Parasite & 2.331 & 0.0002 & 6.079 & 0.0002 \\
\hline Herbivore & 3.1194 & 0.0002 & 3.42 & 0.0002 \\
\hline
\end{tabular}



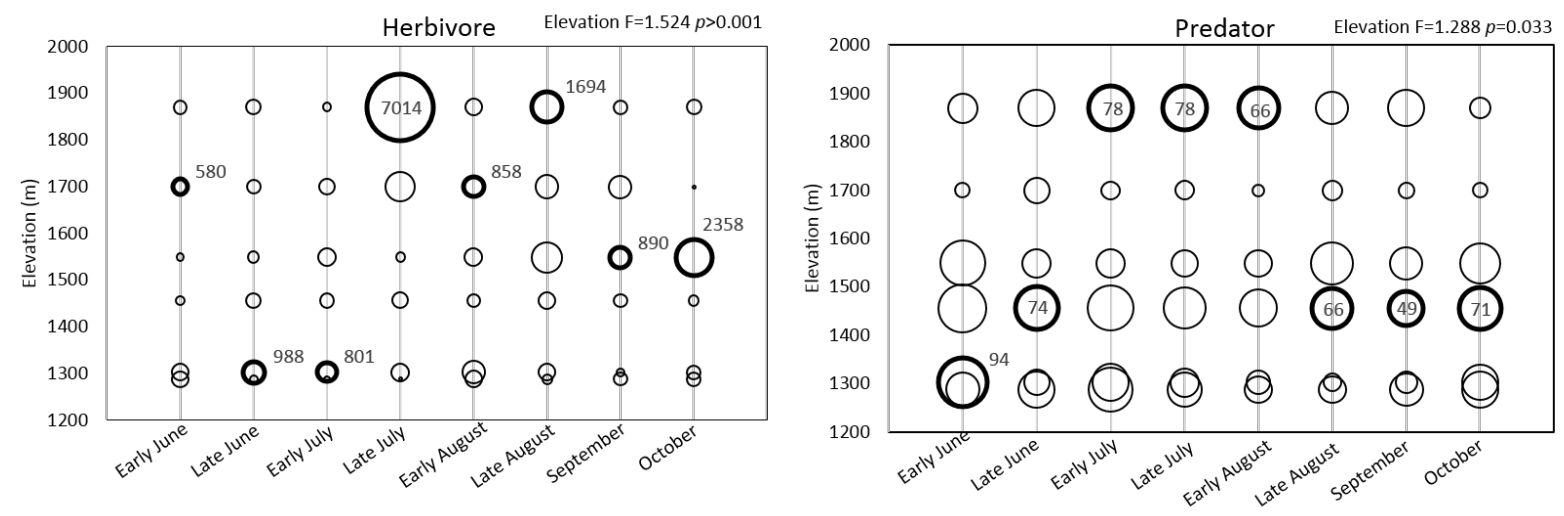

Figure 17. Abundance of herbivores and predators varied among elevations within sampling events, Stinkingwater and Pueblo Mountains, Oregon. The elevation with the highest abundance in each sampling event is drawn in bold and has the number of individuals captured near or inside of it.

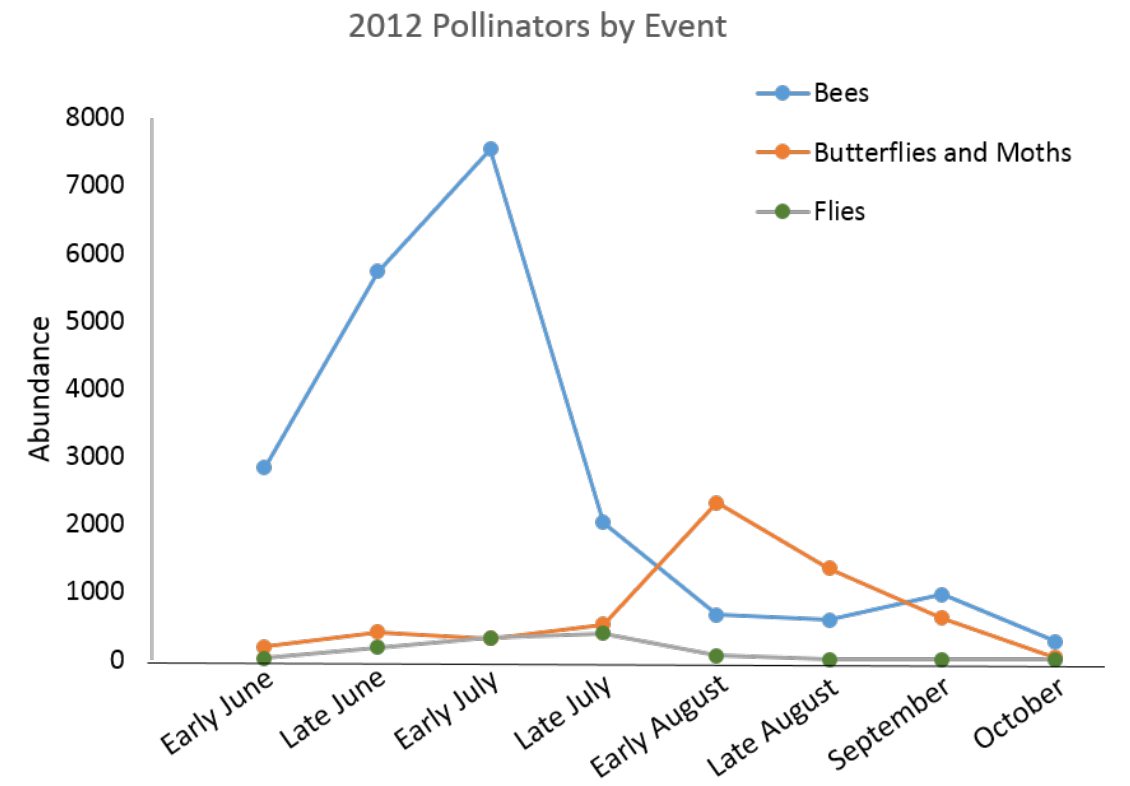

Figure 18. Abundance of pollinators from early June to October 2012 at the Stinkingwater and Pueblo Mountain study areas, Oregon. Bees were the most abundant pollinator in the early season, butterflies and moths were more commonly collected later in the season. 
Table 15. Guilds were associated with weather variables to varying degrees at the Stinkingwater and Pueblo Mountain study areas, Oregon. In this analysis, some guilds were best explained by three predictor variables while others were best explained by two predictor variables. The abundances of detritivores and predators were most strongly associated with weather, parasites were moderately associated, and herbivores and nectarivores were only weakly associated with the measured weather variables.

[High $\mathrm{xR}^{2}$ values indicate a strong non-linear relationship between the feeding guild and the climate variable.]

\begin{tabular}{|l|c|l|l|l|}
\hline \multicolumn{1}{|c|}{ Guild } & \multicolumn{1}{c|}{$\mathbf{X R}^{2}$} & \multicolumn{1}{c|}{ Variable 1 } & Variable 2 & Variable 3 \\
\hline Detritivore & 0.3244 & Elevation & $\begin{array}{c}\text { Minimum air } \\
\text { temperature }\end{array}$ & \\
\hline Herbivore & 0.0623 & Growing degree days & $\begin{array}{c}\text { Maximum solar } \\
\text { radiation }\end{array}$ & \\
\hline Nectarivore & 0.0841 & Elevation & Maximum humidity & \\
\hline Parasite & 0.1842 & $\begin{array}{l}\text { Variance of ground } \\
\text { temperature }\end{array}$ & $\begin{array}{c}\text { Maximum air } \\
\text { temperature }\end{array}$ & $\begin{array}{c}\text { Minimum air } \\
\text { temperature }\end{array}$ \\
\hline Predator & 0.3135 & Elevation & Maximum humidity & \\
\hline
\end{tabular}

Table 16. Differences in composition and abundances in nectarivorous orders of insects among events and elevations within events.

[Orders include nectarivorous members of bees (Hymenoptera), flies (Diptera), and butterflies and moths (Lepidoptera); $\mathrm{F}=$ the magnitude of differences among groups, $\mathrm{p}=$ the likelihood of a type II error]

\begin{tabular}{|c|l|c|c|c|c|}
\hline Metric & & \multicolumn{2}{|c|}{ Elevation } & \multicolumn{2}{c|}{ Event } \\
\hline \multirow{4}{*}{ Composition } & Order & $\mathbf{F}$ & $\mathbf{p}$ & $\mathbf{F}$ & $\boldsymbol{p}$ \\
\cline { 2 - 6 } & Hymenoptera & 3.2 & 0.0002 & 16.221 & $<0.0001$ \\
\cline { 2 - 6 } & Diptera & 3.352 & 0.0002 & 14.654 & 0.0002 \\
\cline { 2 - 6 } & Lepidoptera & 2.668 & 0.0002 & 15.041 & 0.0002 \\
\hline \multirow{3}{*}{ Abundance } & Hymenoptera & 13.077 & 0.0002 & 3.0428 & 0.0002 \\
\cline { 2 - 6 } & Diptera & 20.127 & 0.0002 & 2.7434 & 0.0002 \\
\cline { 2 - 6 } & Lepidoptera & 21.854 & $<0.0001$ & 2.0631 & 0.0002 \\
\hline
\end{tabular}


h) When we associated the abundance of nectarivorous insect orders with weather variables, we found that flies were the most strongly associated group, with 21.9 percent of the variance in abundance explained by the variability of air temperatures and solar radiation (table 17). Bees, butterflies, and moths were poorly associated with the measured weather variables, with only 3.5 and 1.8 percent of the variation in abundance explained. Although associations for two groups were weak, all three were associated with solar radiation. Plots and events with higher solar radiation had fewer pollinators.

Table 17. Associations between nectarivorous insect orders and weather variables. Flies were the only pollinator group that associated strongly with the measured weather variables at our study areas.

[Orders include nectarivorous members of bees (Hymenoptera), flies (Diptera), and butterflies and moths (Lepidoptera); High $\mathrm{xR}^{2}$ values indicate a strong non-linear relationship between elevation and the climate variable.]

\begin{tabular}{|l|c|l|c|l|c|}
\hline & $\mathbf{x R}^{\mathbf{2}}$ & Variable 1 & Tolerance & Variable 2 & Tolerance \\
\hline Diptera & 0.2186 & STDAir & 3.41281 & MaxSolar & 89.75416 \\
\hline Hymenoptera & 0.0349 & GDD & $1,309.807$ & Max Solar & 89.75416 \\
\hline Lepidoptera & 0.0175 & STDGrnd & 1.99265 & Max Solar & 448.7708 \\
\hline
\end{tabular}

\section{Interpretation}

\section{Weather, Elevation, and the Timing of Emergence and Diapause}

We found evidence that the emergence and diapause timing of insects is dependent on environmental cues associated with seasonal and elevational differences in weather. We captured more families for the first and last time at low elevation plots, but more families overall at high elevation plots. This could indicate that insects from the same groups have longer active seasons at lower elevations, or that some insect taxa may have migrated seasonally along an elevation gradient to track favorable weather conditions. Seasonal migrations of insects in temperate zones often involve movements to and from diapause sites (Dingle, 1982). Ashton and others (2009) found that larvae of a rare mountain butterfly species modify their behavior along an elevation gradient to regulate temperature. If climate change patterns continue as predicted and high elevation sites continue to warm, it is possible that insect taxa that regulate temperature through seasonal migration up and down elevation gradients may become stranded in unsuitable habitat at the tops of warming elevation clines, especially during the hottest and driest times in their active season. 


\section{Variability in Guild Abundance Throughout the Active Season}

We found that the most abundant families had peak abundances that were staggered through the active season. Seasonal changes in temperature and precipitation were greater than changes among elevations within the same sampling period. These staggered peaks in abundance may be examples of adaptive seasonality, which allows insect taxa to avoid temperatures outside of their thermal tolerance or, in the case of thermally tolerant taxa, to avoid competition from more thermally limited taxa (Powell and Logan, 2005). Univoltine species, such as most insects in temperate regions, are especially sensitive to continuously increasing temperatures that are associated with climate change. Relatively infrequent, extreme (high) temperature events can result in large decreases in reproduction due to reduced survival of immature individuals (Kingsolver and others, 2011).

\section{Pollinators, Seasonality, and Climate Change}

Pollinators are a group of particular interest due to their economic and ecological importance. We found that the peak abundances of bees and butterflies, the most abundant pollinators, were staggered through time. Bees from the family Halictidae were especially abundant in the early summer and moths from the family Tortricidae were especially abundant in the late summer. Colonial thermoregulation is common in social bees, such as European honey bees (Kronenberg and Heller, 1982), but Halictid bees, as well as most native bees in this region, are solitary. In this case, bees may avoid foraging (and pollinating) at high temperatures (Heinrich, 1975). High temperatures have also been shown to adversely affect reproduction in Tortricid moths (Carroll and Quiring, 1992). Large females generally produced more eggs under control temperatures, but had reduced fecundity and longevity under conditions of increased temperature.

\section{Management Implications and Future Directions}

Measurements of changes in climate and weather along elevation gradients provide a unique opportunity to study the effects of climate on communities while controlling for factors such as genetic adaptation in or among populations. These factors are confounded with climate effects in studies that measure responses over large areas encompassing many latitudes (Hill and others, 2011; Simberloff, 2009).

Information derived from our analyses can be applied to make predictions regarding the current and future distribution of insects in a highly disturbed and economically important semi-arid ecosystem. The analysis technique and information produced by this project could be used in future studies to help predict habitat quality and locations for organisms of interest, such as pollinators.

The plan for the second phase of this project is to assess changes in species ranges and phenology 10 years or more after this study at the same established sampling plots. Ideally this would occur in the years 2022-2025, because many climate forecasts predict changes for the years 2025 and 2050. We could address questions such as: (1) Have species ranges shifted over time? (2) How have community composition and species abundance and phenology changed over time? (3) Have changes been uniform throughout elevation gradients? (4) Have some species been affected more strongly at specific elevations? This second phase of the project could provide important data that can be used to develop better species-climate models and predict how insect communities will be affected by continued climate change. 


\section{References Cited}

Arkle, R.S., Pilliod, D.S., Hanser, S.E., Brooks, M.L., Chambers, J.C., Grace, J.B., Knutson, K.C., Pyke, D.A., Welty, J.L., and Wirth, T.A., 2014, Quantifying restoration effectiveness using multiscale habitat models-Implications for sage-grouse in the Great Basin: Ecosphere v. 5, no. 3 p. 1-32.

Arnold, S.E., Savolainen, J.V., and Chittka, L., 2009, Flower colours along an alpine altitude gradient, seen through the eyes of fly and bee pollinators: Arthropod-Plant Interactions. v. 3, p. 27-43.

Ashton, S., Gutierrez, D., and Wilson, R.J., 2009, Effects of temperature and elevation on habitat use by a rare mountain butterfly-Implications for species responses to climate change: Ecological Entomology, v. 34, no., 4, p. 437-446.

Balch, J., Bradley, B.A., D'Antonio, C.M., and Gómez-Dans, J., 2013, Introduced annual grass increases regional fire activity across the arid western USA (1980-2009): Global Change Biology, v. 19, p. 173-183.

Balmford, A., Jayasuriya, A.H.M., and Green, M.J.B., 1996, Using higher-taxon richness as a surrogate for species richness-II. Local applications: Proceedings of the Royal Society of London Biology, v. 263, p. 1,571-1,575.

Bird, J.M., and Hodkinson, I.D., 1999, Species at the edge of their range-The significance of the thermal environment for the distribution of congeneric Craspedlepta species (Sternorrhyncha:Psylloidea) living on Epilobium angustifolium (Onagraceae): European Journal of Entomology, v. 96, p. 103-109.

Booth, D.T., Cox, S.E., Meikle, T.W., and Fitzgerald, C., 2006, The accuracy of ground-cover measurements: Rangeland Ecology and Management, v. 59, p. 179-188.

Buckley, L.B., Miller, E.F., and Kingsolver, J.G., 2013, Ectotherm thermal stress and specialization across altitude and latitude-Intergative and comparative biology 1-11.

Cagnolo, L., Molina, S.I., and Valladares, G.R., 2002, Diversity and guild structure of insect assemblages under grazing and exclusion regimes in a montane grassland from Central Argentina: Biodiversity and Conservation, v. 11, p. 407-420.

Carroll, A.L., and Quiring, D.T., 1993, Interactions between size and temperature influence fecundity and longevity of a tortricid moth, Zeiraphera Canadensis: Oecologia v. 93, p. 233-241.

Chao, A., and Jost, L., 2012: Coverage-based rarefaction and extrapolation-Standardizing samples by completeness rather than size: Ecology v. 93, no. 12, p. 2,533-2,547.

Colwell, R.K., 2013, EstimateS: Statistical estimation of species richness and shared species from samples. Version 9. User's guide and application published at: http://purl.oclc.org/estimates.

Crawford, J.A., Olson, R.A., West, N.E., Mosley, J.C., Schroeder, M.A., Whitson, T.D., Miller, R.F., Gregg, M.A., and Boyd, C.S., 2004, Ecology and management of sage-grouse and sage-grouse habitat: Journal of Range Management, v. 57, p. 2-19.

Devoto, M, Medan, D., and Montaldo, N.H., 2005, Patterns of interaction between plants and pollinators along an environmental gradient: OIKOS, v. 109, p. 461-472.

Dingle, Hugh, 1982, Function of migration in the seasonal synchronization of insects: Entomologia Experimentalis et Applicata, v. 31, no. 1, p. 36-48.

Drut, M.S., Pyle, W.H., and Crawford, J.A., 1994, Technical note-Diets and food selection of sage grouse chicks in Oregon: Journal of Range Management, v. 47, p. 90-93.

Dunne, J.A., Saleska, S.R., Fisher, M.L., and Harte, J., 2004, Integrating experimental and gradient methods in ecological climate change research: Ecology, v. 85, no. 4, p. 904-916.

Gienapp, P., Leimul, R., and Meriläl J., 2007, Responses to climate change in avian migration timemicroevolution versus phenotypic plasticity: Climate Research, v. 35, p. 25-35. 
Heino, J., and Soininen, Janne, 2007, Are higher taxa adequate surrogates for species-level assemblage patterns and species richness in stream organisms?: Biological Conservation, v. 137, p. 78-89.

Heinrich, B., 1975, Thermoregulation in bumblebees: Journal of Comparative Physiology, v. 96, no. 2, p. 152-166.

Hickling, R., Roy, D.B., Hill, J.K., and Thomas, C.D., 2005, A northward shift of range margins in British Odonata: Global Change Biology, v. 11, p. 502-506.

Hill, J.K., Griffiths, H.M., and Thomas, C.D., 2011, Climate change and evolutionary adaptations at species’ range margins: Annual Review of Entomology, v. 56, p. 143-159.

Hodkinson, I.D., 2005, Terrestrial insects along elevation gradients-Species and community response to altitude: Biological Review v. 80, p. 489-513.

Hoekstra, J.M., Boucher, T.M., Ricketts, T.H., and Roberts, C., 2005, Confronting a biome crisis: global disparities of habitat loss and protection: Ecology Letters, v. 8, p. 23-29.

Johnson, G.D. and Boyce, M.S., 1990, Feeding trials with insects in the diet of sage grouse chicks: The Journal of Wildlife Management, v. 54, p. 89-91.

Karl, T.R., Melillo, J.M., and Peterson, T.C., eds., 2009, Global climate change impacts in the United States-A state of knowledge report from the United States Global Change Research Program: New York, Cambridge University Press, 188 p.

Kearns, C.A., 1992, Anthophilous fly distribution across an elevation gradient. The American midland naturalist 127(1):172-182.

Kelly, A.E., and Goulden, M.L., 2008, Rapid shifts in plant distribution with recent climate change: Proceedings of the National Academy of Science of the United States of America, v. 105, p. 11,823$11,826$.

Kingsolver, J.G., Woods, H.A., Buckley, L.B., Potter, K.A., MacLean, H.J., and Higgins, J.K., 2011, Complex life cycles and the responses of insects to climate change: Integrative and Comparative Biology, v. 51, p. 719-732.

Knick, S.T., 1999, Requiem for a sagebrush ecosystem? Northwest Science 73:53-57.

Knutson, K., Pyke, D, Wirth, T., Arkle, R., Pilliod, D., Brooks, M., Chambers, J., and Grace, J., 2014, Long-term effects of seeding after wildfire on vegetation in Great Basin shrubland ecosystems: Journal of Applied Ecology, v. 51, p. 1,414-1,424.

Kronenberg, F., and Heller, C., 1982, Colonial thermoregulation in honey bees (Apis mellifera). Journal of comparative physiology, v. 148, p 65-76.

Longcore, T., 2003, Terrestrial arthropods as indicators of ecological restoration success in coastal sage scrub (California, U.S.A.): Restoration Ecology, v. 11, no. 4, p. 397-409.

Lowe, C.C., Birch, S.M., Cook, S.P., and Merickel, F., 2010, Comparison of trap types for surveying insect communities in Idaho sagebrush steppe: The Pan-Pacific Entomologist, v. 86, no. 2, p. 47-56.

McCune, B., 2007, Improved estimates of incident radiation and heat load using non-parametric regression against topographic variables: Journal of Vegetation Science, v. 18, p. 751-754.

McCune, B, 2011, Nonparametric multiplicative regression for habitat modeling; Corvallis, Oregon, Oregon State University, 58 p., accessed November 7, 2015, at http://www.pcord.com/NPMRintro.pdf.

McGee, J.M., 1982, Small mammal populations in an unburned and early fire successional sagebrush community: Journal of Range Management, v. 35, p. 177-180.

Miller, R.F., and Edelman, L.L., 2000, Spatial and temporal changes of sage grouse habitat in the sagebrush biome:. Corvallis, Oregon, Oregon State University, Agricultural Experiment Station, Technical Bulletin 151. 
Pachauri, R.K., and Meyer, L.A., eds., 2014, Climate change 2014—Synthesis report—Contribution of working groups I, II and III to the fifth assessment report of the Intergovernmental Panel on Climate Change: Geneva, Switzerland, Intergovernmental Panel on Climate Change, 151 p.

Pilliod, D.S., and Arkle, R.S., 2013, Performance of quantitative vegetation sampling methods across gradients of cover in Great Basin plant communities: Rangeland Ecology and Management, v. 66, no. 6, p. 634-647.

The White House, 2015, Pollinator research action plan-Report of the pollinator health task force: The White House Web page, Office of Science and Technology Policy Blog, May 19, 2015, 92 p., accessed February 12, 2016.

https://www.whitehouse.gov/sites/default/files/microsites/ostp/Pollinator\%20Research\%20Action\%2 0Plan\%202015.pdf.

Powell, J.A., and Logan, J.A., 2005, Insect seasonality-Circle map analysis of temperature-driven life cycles: Theoretical Population Biology, v. 67, no. 3, p. 161-179.

Riggins, J.J., Davis, C.A,. and Hoback, W.W., 2009, Biodiversity of belowground invertebrates as an indicator of wet meadow restoration success (Platte River, Nebraska): Restoration Ecology, v. 17, no. 4, p. 495-505.

Root, T.L., Price, J.T., Hall, K.R., Schneider, S.H., Rosenzweig, C., and Pounds, J.A., 2003, Fingerprints of global warming on wild animals and plants: Nature, v. 421, p. 57-60.

Roulston, T.H., Smith, S.A., Brewster, A.L., 2007, A comparison of pan trap and intensive net sampling techniques for documenting a bee (Hymenoptera-Apiformes) fauna: Journal of the Kansas Entomological Society, v. 80, no. 2, p., 179-181.

Sala, O.E., Chapin, F.S., III, Armesto, J.J., Berlow, E., Bloomfield, J., Dirzo, R., Huber-Sanwald, E., Huenneke, L.F., Jackson, R.B., Kinzig, A., Leemans, R., Lodge, D.M., Mooney, H.A., Oesterheld, M., Poff, N.L., Sykes, M.T., Walker, B.H., Walker, M., and Wall, D.H., 2000, Global biodiversity scenarios for the year 2100: Science, v. 287, p. 1,770-1,774.

Simberloff, D., 2009, The role of propagule pressure in biological invasions: Annual Review of Ecology, Evolution, and Systematics, v. 40, p. 81-102.

Thornton, P.E., Thornton, M.M., Mayer, B.W., Wilhelmi, N., Wei, Y., Devarakonda, R., and Cook, R.B., 2014, Daymet-Daily surface weather data on a 1-km grid for North America, Version 2: ORNL DAAC, Oak Ridge, Tennessee (https://daac.ornl.gov/cgi-bin/dsviewer.pl?ds_id=1219). Accessed April 11, 2016.

U.S. Bureau of Land Management, 2015, Oregon greater sage-grouse approved resource management plan amendment: Prepared by US Department of the Interior Bureau of Land Management Oregon/Washington State Office, BLM/OR/A/PL-15/051+1792, 252 p.

Vitousek, P.M., 1994, Beyond global warming-Ecology and global change: Ecology, v. 75, p. 1,8611,876 .

Vitousek, P.M., D’Antonio, C.M., Loope, L.L., and Westbrooks, R., 1996, Biological invasions as global environmental change: American Scientist, v. 84, p. 468-478.

Warren, S.D., Harper, K.T., and Booth G.M., 1988, Elevational distribution of insect pollinators: American Midland Naturalist, v. 120, no. 2, p. 325-330.

West, N.E., 1999, Managing for biodiversity of rangelands, in Collins, P.W.W., and Qualset, C.O., eds., Biodiversity in agroecosystems: Boca Raton, Florida, CRC Press, p. 101-126.

Whittaker, R.H., and Niering, W.A., 1975, Vegetation of the Santa Catalina Mountains, Arizona. V. Biomass, production, and diversity along the elevation gradient: Ecology, v. 56, p. 771-790.

Williams, D.F., 1984, Habitat associations of some rare shrews (Sorex) from California: Journal of Mammalogy, v. 65, no. 2, 325-328. 
Williams, P.H., and Gaston, K.J., 1994, Measuring more of biodiversity—Can higher taxon richness predict wholesale species richness?: Biological Conservation, v. 67, p. 211-217.

Wilson, J.S., Griswold, T., and Messinger, O.J., 2008, Sampling bee communities

(Hymenoptera:Apiformes) in a desert landscape-Are pan traps sufficient?: Journal of the Kansas Entomological Society, v. 81, no. 3, p. 288-300. 
Publishing support provided by the U.S. Geological Survey Science Publishing Network, Tacoma Publishing Service Center

For more information concerning the research in this report, contact the Director, Forest and Rangeland Ecosystem Science Center U.S. Geological Survey

777 NW 9th St., Suite 400

Corvallis, Oregon 97330

http://fresc.usgs.gov/ 
